\title{
The origin of aubrites: Evidence from lithophile trace element abundances and oxygen isotope compositions.
}

\author{
J.A. Barrat ${ }^{1}$, R.C. Greenwood ${ }^{2}$, K. Keil ${ }^{3}$, M.L. Rouget ${ }^{4}$, \\ J.S. Boesenberg ${ }^{5}$, B. Zanda ${ }^{6}$, and I.A. Franchi ${ }^{2}$
}

1: U.B.O.-I.U.E.M., CNRS UMR 66538 (Domaines Océaniques), Place Nicolas Copernic, 29280 Plouzané, France. E-Mail: barrat@univ-brest.fr. (corresponding author).

2: Planetary and Space Sciences, Department of Physical Sciences, The Open University, Walton Hall, Milton Keynes, MK76AA,United Kingdom.

3: Hawaii Institute of Geophysics and Planetology, School of Ocean and Earth Science and Technology, University of Hawaii at Manoa, Honolulu, HI 96822, USA.

4: CNRS UMS 3113, I.U.E.M., Place Nicolas Copernic, 29280 Plouzané Cedex, France.

5: Earth and Planetary Sciences, American Museum of Natural History, New York, NY 10024, USA, and Geological Sciences, Brown University, Providence, RI 02912, USA.

6: Muséum National d'Histoire Naturelle, Laboratoire de Minéralogie et de Cosmochimie du Muséum, CNRS UMR7202, 61 rue Buffon, 75005 Paris, France.

submitted to Geochimica et Cosmochimica Acta, 4/26/16

revised manuscript, 7/2/16 
We report the abundances of a selected set of "lithophile" trace elements (including lanthanides, actinides and high field strength elements) and high-precision oxygen isotope analyses of a comprehensive suite of aubrites. Two distinct groups of aubrites can be distinguished: a) the maingroup aubrites display flat or light-REE depleted REE patterns with variable Eu and Y anomalies; their pyroxenes are light-REE depleted and show marked negative Eu anomalies; b) the Mount Egerton enstatites and the silicate fraction from Larned display distinctive light-REE enrichments, and high $\mathrm{Th} / \mathrm{Sm}$ ratios; Mount Egerton pyroxenes have much less pronounced negative Eu anomalies than pyroxenes from the main-group aubrites.

Leaching experiments were undertaken to investigate the contribution of sulfides to the whole rock budget of the main-group aubrites. Sulfides contain in most cases at least $50 \%$ of the REEs and of the actinides. Among the elements we have analyzed, those displaying the strongest lithophile behaviors are $\mathrm{Rb}, \mathrm{Ba}, \mathrm{Sr}$ and $\mathrm{Sc}$.

The homogeneity of the $\Delta^{17} \mathrm{O}$ values obtained for main-group aubrite falls $\left[\Delta^{17} \mathrm{O}=+0.009 \pm 0.010\right.$ $\%_{0}(2 \sigma)$ ] suggests that they originated from a single parent body whose differentiation involved an early phase of large-scale melting that may have led to the development of a magma ocean. This interpretation is at first glance in agreement with the limited variability of the shapes of the REE patterns of these aubrites. However, the trace element concentrations of their phases cannot be used to discuss this hypothesis, because their igneous trace-element signatures have been modified by subsolidus exchange. Finally, despite similar $\mathrm{O}$ isotopic compositions, the marked light-REE enrichments displayed by Mount Egerton and Larned suggest that they are unrelated to the main-group aubrites and probably originated from a distinct parent body. 
Among the approximately fifty thousand officially classified meteorites held in institutional collections, enstatite-rich types are rare (about five hundred specimens) and of these, the aubrites are particularly scarce; with only nine falls and a score of finds, including pairings. The mineralogy, geochemistry and isotopic composition of aubrites demonstrate that they are unusual and intriguing achondrites (predominantly pyroxenites) (e.g., Keil, 2010). Most are breccias, containing clasts of coarse-grained pyroxenite that formed in a slowly-cooled environment (plutons), embedded in a clastic matrix composed mainly of enstatite crystal debris. Aubrites are mineralogically diverse, consisting mainly of enstatite, with various proportions of diopside, inverted pigeonite, forsterite, albitic plagioclase, as well as small amounts of troilite and metallic Fe,Ni. In addition, they contain a host of rare accessory sulfides, including oldhamite $(\mathrm{CaS})$, ferroan alabandite $[(\mathrm{Mn}, \mathrm{Fe}) \mathrm{S}]$, daubréelite $\left(\mathrm{FeCr}_{2} \mathrm{~S}_{4}\right)$ and caswellsilverite $\left(\mathrm{NaCrS}_{2}\right)$, all of which formed, under extremely low oxygen fugacities (see Keil, 2010, for a review). As such, aubritic pyroxenites are magmatic rocks that crystallized under the most reducing conditions yet identified $\left(f \mathrm{O}_{2} \approx \mathrm{IW}-5\right.$ or below, e.g., Fogel, 1998).

Two of them (Mount Egerton and Larned) are anomalous, with high metal contents. Shallowater, a non-brecciated orthopyroxenite containing large orthoenstatite crystals (up to $4.5 \mathrm{~cm}$ ), was previously identified as an anomalous aubrite by Keil et al. (1989). It experienced a complex history and almost certainly formed on a separate parent body to that of the main-group aubrites (Keil et al., 1989; Rubin, 2015); an interpretation that is in agreement with Hf-W systematics (Petitat et al., 2008) and $\mathrm{Zn}$ isotopes (Moynier et al., 2011). In addition to these aubritic samples, a few other enstatite achondrites are known, such as Itqiy and Northwest Africa 2526. However, these rocks are certainly unrelated to aubrites (e.g., Keil and Bischoff, 2008).

The occurrence of oldhamite and other unusual sulfides indicates that the chemical affinities of many "traditionally" lithophile elements were modified by the prevailing reducing conditions, such that they display a strongly chalcophile behaviour. Sulfides, and particularly oldhamite, are major rare earth element (REE) carriers in aubrites (e.g., Floss and Crozaz, 1993; Lodders et al., 1993; Wheelock et al., 1994, Newsom et al., 1996). Thus, REE and possibly other refractory lithophile elements show a 
unique evolution during the differentiation of the aubrite parent body (bodies) and during the genesis and crystallization of aubritic parental melts.

Contrary to other achondrites, for which the composition of their parental materials remains a matter for discussion, it is almost certain that the aubrites are the early differentiation products of an enstatite chondrite-related precursor. Aubrites and enstatite chondrites clearly formed under similar, extremely reducing formation conditions and in addition display almost identical isotopic compositions for many elements (e.g., O, Ti, Cr, S, Si, Clayton and Mayeda, 1996; Newton et al., 2000; Miura et al., 2007; Trinquier et al., 2007; Zhang et al., 2012; Savage and Moynier, 2013; Defouilloy et al., 2016). This suggests that their parent body (or bodies) accreted from materials which condensed in similar regions of the solar nebula. Both enstatite chondrites and aubrites show many isotopic similarities to the Earth and this has led to the suggestion that the proto-Earth accreted from enstatite-like precursor materials (Javoy et al., 2010).

In this paper, we report the trace element abundances obtained by Inductively Coupled Plasma Mass Spectrometry (ICP-MS) for a comprehensive suite of the "common" or main-group aubrites and the two anomalous metal-rich aubrites (Mount Egerton and Larned). Our aim is, first, to evaluate the full range of refractory lithophile element distributions displayed by these meteorites, in order to estimate how sulfides control the budget of these elements. Secondly, we report new high precision oxygen isotope analyses for a representative suite of aubrites and examine whether their parent body (bodies) went through an early phase of large-scale melting (magma ocean stage?).

\section{Samples and Analytical Methods}

We obtained samples from the classical aubrites (Aubres, Bishopville, Bustee, Cumberland Falls, Khor Temiki, LAP 03719, LAR 04316, Mayo Belwa, Norton Co., Peña Blanca Spring, Pesyanoe) and from two anomalous metal-rich finds (Mount Egerton and Larned). Sample sources are listed in Table 1. Powders were prepared using a boron-carbide mortar and pestle. Elemental abundances for most of the samples were determined using a high-resolution ICP-MS spectrometer Thermo Element 2 at Institut Universitaire Européen de la Mer (IUEM), Plouzané, following well- 
established procedures (e.g., Barrat et al., 2012). Results for international standards (BIR1, JB2, WS-

E, UB-N, PCC1, Allende powder USNM 3529) have been reported previously (Barrat et al., 2012, 2014).

A series of leaching experiments were undertaken to investigate the contribution of sulfides to whole rock budgets, and to determine the trace element abundances of the insoluble silicate fraction. It is important to emphasize that, contrary to other types of achondrites, aubrites are totally devoid of either apatite or merrillite; phases which are usually important carriers of REEs or actinides in many other types of meteorites. Consequently, sulfides, and notably oldhamite, are here the sole REE-rich phases, and are easily dissolved in $\mathrm{HCl}$ (e.g., Lodders et al., 1993). Some of the meteorite powders (typically 100-200 mg) were leached in hot $6 \mathrm{~N} \mathrm{HCl}\left(1\right.$ hour, $\left.120^{\circ} \mathrm{C}\right)$, to dissolve all the sulfides (including troilite) and the metallic $\mathrm{Fe}, \mathrm{Ni}$, leaving residues composed essentially of insoluble phases (mainly enstatite and sometimes diopside and plagioclase). The composition of the leachates mirror that of the bulk sulfides, with the exception of those elements present in both sulfides and metal (e.g., $\mathrm{Fe}, \mathrm{Ni}$ ). The composition of the metal phase in aubrites was not investigated in this study. The leachates were separated by centrifuge and the residues were then rinsed five times in ultrapure water. Residues were dried and processed using the same methodology as employed for the other meteorite powders. One sample (Aubres A1) displays very low light REE abundances $(<0.01 \times \mathrm{CI})$. Its REEs have been separated from the major elements and concentrated before analysis following the method described by Barrat et al. (1996).

Some of the leachates were analyzed for REE and $\mathrm{Ca}$ abundances. The $\mathrm{Ca}$ abundances were arbitrarily fixed at $52 \mathrm{wt} \%$ (equivalent to the Ca-concentration in oldhamite), and the other element abundances were calculated accordingly. These abundances are certainly accurate for most of the samples in which oldhamite is the main REE-bearing sulfide. We cannot exclude the possibility that in some cases the involvement of other sulfides (e.g., if ferroan alabandite was exceptionally abundant) might potentially compromise these calculations. However, the shapes of the REE patterns or the ratios calculated using these abundances (e.g., $\mathrm{La} / \mathrm{Sm}, \mathrm{Eu} / \mathrm{Eu}^{*}$, etc...) are as accurate as the results obtained with bulk samples or residues. 

al., 2012, 2014, 2016), the precision for abundances in powdered samples and residues is much better than $5 \%$. The precision for trace element ratios (e.g., $\mathrm{Eu} / \mathrm{Eu}^{*}, \mathrm{~Tb} / \mathrm{Tb}^{*}$, and $\mathrm{Yb} / \mathrm{Yb}^{*}$, where $\mathrm{Eu}^{*}, \mathrm{~Tb}^{*}$ and $\mathrm{Yb}^{*}$ are respectively the interpolated $\mathrm{Eu}, \mathrm{Tb}$ and $\mathrm{Yb}$ concentrations for a smooth $\mathrm{CI}$-normalized REE pattern, such that $\mathrm{Eu}_{\mathrm{n}}{ }_{\mathrm{n}}=\left(\mathrm{Sm}_{\mathrm{n}} \times \mathrm{Gd}_{\mathrm{n}}\right)^{1 / 2}, \mathrm{~Tb}_{\mathrm{n}}=\left(\mathrm{Gd}_{\mathrm{n}} \times \mathrm{Dy}_{\mathrm{n}}\right)^{1 / 2}$ and $\left.\mathrm{Yb}_{\mathrm{n}}=\mathrm{Er}_{\mathrm{n}}{ }^{1 / 3} \times \mathrm{Lu}_{\mathrm{n}}{ }^{2 / 3}\right)$ is better than $2.5 \%$ ( $2 \times$ relative standard deviation).

Oxygen isotope analyses were carried out at The Open University using an infrared laser fluorination system following the methods and procedures of Miller et al. (1999). Oxygen was released from the sample by heating in the presence of $\mathrm{BrF}_{5}$. After fluorination, the released oxygen gas was purified by passing it through two cryogenic nitrogen traps and over a bed of heated $\mathrm{KBr}$. Oxygen gas was analysed using a MAT 253 dual inlet mass spectrometer. Interference at $\mathrm{m} / \mathrm{z}=33$ by the $\mathrm{NF}_{3}$ fragment ion $\mathrm{NF}^{+}$was monitored by performing scans for $\mathrm{NF}_{2}^{+}$on all samples. In all cases $\mathrm{NF}_{2}$ was either negligible or absent. Oxygen isotopic analyses are reported in standard $\delta$ notation, where $\delta^{18} \mathrm{O}$ has been calculated relative to VSMOW (Vienna Standard Mean Ocean Water) as $\delta^{18} \mathrm{O}=$ $\left[\left({ }^{18} \mathrm{O} /{ }^{16} \mathrm{O}_{\text {sample }}\right) /\left({ }^{18} \mathrm{O} /{ }^{16} \mathrm{O}_{\text {vSmow }}\right)-1\right] \times 1000(\%)$ and similarly for $\delta^{17} \mathrm{O}$ using the ${ }^{17} \mathrm{O} /{ }^{16} \mathrm{O}$ ratio. $\Delta{ }^{17} \mathrm{O}$, which represents the deviation from the terrestrial fractionation line, has been calculated throughout using a linearized format (Miller, 2002):

$$
\Delta^{17} \mathrm{O}=1000 \ln \left(1+\delta^{17} \mathrm{O} / 1000\right)-\lambda 1000 \ln \left(1+\delta^{18} \mathrm{O} / 1000\right)
$$

where $\lambda=0.5247$, which was determined using 47 terrestrial whole-rock and mineral separate samples (Miller et al., 1999; Miller, 2002).

The overall precision obtained by laser fluorination is essentially controlled by the fluorination reaction itself and the subsequent sample clean-up stages prior to the entry of the oxygen gas into the bellows of the dual inlet mass spectrometer (Greenwood et al., 2016). Sample chemistry certainly plays a significant role in determining the level of precision obtained by laser fluorination. The highest levels of precision using the Open University system are generally obtained on materials with a relatively high $\mathrm{SiO}_{2}$ content. Thus, 38 repeat analyses of our internal obsidian standard gave the following levels of precision: $\pm 0.053 \%$ ( $2 \sigma)$ for $\delta^{17} \mathrm{O} ; \pm 0.095 \%$ ( $\left.2 \sigma\right)$ for $\delta^{18} \mathrm{O} ; \pm 0.017 \%$ ( $\left.2 \sigma\right)$ for $\Delta^{17} \mathrm{O}$ 
164 (Starkey et al., 2016). The lower level of precision obtained in the present study (Table 4) compared with our internal obsidian standard is most probably a reflection of variability in the fluorination reaction for orthopyroxene-rich materials.

\section{Results}

Most aubrites are breccias, often comprising a variety of lithologies, as exemplified by Norton County (Okada et al., 1998). Obtaining a representative sample of a breccia would require crushing and homogenization of tens of grams of sample. Such large amounts of aubrites are just not obtainable for bulk rock analyses. Instead, we have prepared powders ( 0.5 to $2 \mathrm{~g}$ ) from chips of "matrix", which represent the fine-grained portion of samples, devoid of large clasts (> 3-4 mm) of enstatite. This matrix-rich fraction is likely to be a reasonable reflection of the overall composition of the whole rock provided the sample has not experienced a significant level of projectile contamination. This latter possibility needs to be evaluated individually for each sample. This can be done by comparing the matrix compositions to that of a pure pyroxene fraction, consequently we also obtained pyroxene fractions or large fragments of enstatite for some of the aubrites.

\subsection{Trace element abundances}

Previous studies have shown that aubrites are poor in "lithophile" trace elements (Masuda, 1967; Wolf et al., 1983; Newsom et al., 1986; Okada et al., 1988; Lodders et al., 1993; Floss and Crozaz, 1993; Wheelock et al., 1994; Keil et al., 2011; Hidaka et al., 2012; Dauphas and Pourmand, 2015; Barrat et al., 2016). Our analyses (Tables 2 and 3) are in agreement with these earlier results. With the notable exception of $\mathrm{Mn}, \mathrm{Ti}, \mathrm{Sc}$ and in some cases $\mathrm{V}, \mathrm{Sr}$ and $\mathrm{Y}$, for which concentrations of > $5 \mu \mathrm{g} / \mathrm{g}$ have been measured, all the other analyzed elements display very low abundances of $<1 \mu \mathrm{g} / \mathrm{g}$. However, because more elements were determined here compared to previous studies, our results can potentially detect some previously unrecognized geochemical anomalies in aubrites.

\subsubsection{Whole rock samples (matrices)}



relative proportions of pyroxene, plagioclase and sulfide, as exemplified by the REEs (Fig. 1). The Yb concentrations range from 0.063 to $0.281 \mu \mathrm{g} / \mathrm{g}$ (Table 2). Except for Aubres and Bishopville, most of the samples are light-REE depleted $\left(\mathrm{La}_{\mathrm{n}} / \mathrm{Sm}_{\mathrm{n}}=0.65-0.94\right)$, with marked negative Eu anomalies $\left(\mathrm{Eu} / \mathrm{Eu}^{*}=0.30-0.69\right)$, and sometimes small $\mathrm{Y}$ and $\mathrm{Yb}$ anomalies $\left(\mathrm{Y}_{\mathrm{n}} / \mathrm{Ho}_{\mathrm{n}}=0.77-1.00, \mathrm{Yb} / \mathrm{Yb}^{*}=0.95\right.$ $1.01)$.

Bishopville has by far the highest plagioclase content (16 vol\%, Watters and Prinz, 1979), and consequently its positive Eu anomaly is not a surprise. Its La enrichment, while the other light REEs are in chondritic proportions, is more unusual $\left(\mathrm{La}_{\mathrm{n}} / \mathrm{Ce}_{\mathrm{n}}=1.56, \mathrm{Ce}_{\mathrm{n}} / \mathrm{Sm}_{\mathrm{n}}=1.06\right)$. It is definitely not an analytical artifact, because a similar pattern was previously obtained for this aubrite by Dauphas and Pourmand (2015) using a different procedure with a distinct sample.

The Aubres matrix exhibits a unique positive $\mathrm{Tb}$ anomaly $\left(\mathrm{Tb} / \mathrm{Tb}^{*}=2.11\right)$ that will be discussed below. We note that the data previously obtained by Wolf et al. (1983), although partial and less accurate, suggest a comparable anomaly (Fig. 2).

\subsubsection{Pyroxenes}

Pyroxenes in aubrites often contain inclusions of REE-rich sulfides which can potentially have a detectable impact on the measured trace element abundances. The contributions of these sulfides are illustrated by Khor Temiki and Norton County. We powdered a fragment of Khor Temiki enstatite. Half of the powder was directly dissolved and the remaining powder was leached in hot $\mathrm{HCl}$ and rinsed with ultrapure water before dissolution. The residue after leaching displays significantly lower abundances for many elements compared to the unleached pyroxene (e.g., $\approx 3-4$ times less light REE than the unleached pyroxene, Figs 2, 3, Table 2). Using the trace element abundances of the unleached pyroxene and of the leachate (see below), we estimate that a contribution of only $0.008 \mathrm{wt} \%$ of oldhamite can explain the abundances determined in the unleached pyroxene. Similarly, we powdered four different chips of a large enstatite crystal (sample E) from Norton County (Table 2). One sample (E1) was acid-digested directly and the three others (E2 to E4) were leached as previously. The results 
obtained with the three leached samples indicate that the crystal was relatively homogeneous. Yet again, the unleached pyroxene shows higher light REE, Sr, Ba, Zr, Hf, Th and $\mathrm{U}$ abundances than the averaged leached pyroxene (Fig. 3). Thus, because of their intrinsically low concentration levels for many trace elements, aubritic pyroxene analyses can be easily distorted by minute amounts of sulfides. To overcome this problem, we have systematically leached with hot $\mathrm{HCl}$ the powders prepared from our pyroxene fractions, in order to remove any potential sulfide inclusions.

The diversity of the trace element contents in the aubritic pyroxenes is illustrated both by their REE abundances, which ranges from $8 \times 10^{-4}$ to $3 \times \mathrm{CI}$, and the shapes of their REE patterns (Fig. 4). Two pyroxene fractions (Larned and Pesyanoe) contained traces of plagioclase that explains their positive Eu anomalies. The Cumberland Falls sample displays the highest REE abundances, suggesting that the crystal was initially pigeonite or contains a sizable amount of diopside. With the exception of these samples, the pyroxene fractions we analyzed were pure enstatite. The REE patterns allow us to distinguish two groups of aubrites. The first group comprises Aubres, Cumberland Falls, Peña Blanca Spring, Khor Temiki, Norton County and Pesyanoe. Their pyroxenes are diversely lightREE depleted $\left(\mathrm{La}_{\mathrm{n}} / \mathrm{Sm}_{\mathrm{n}}=0.08-0.92\right)$ with deep negative $\mathrm{Eu}$ anomalies $\left(\mathrm{Eu} / \mathrm{Eu}^{*}=0.09-0.42\right)$, and varied $\mathrm{Yb} / \mathrm{Yb}^{*}(=0.81-1.04)$ and $\mathrm{Y}_{\mathrm{n}} / \mathrm{Ho}_{\mathrm{n}}$ ratios $(=0.79-1.76)$. The second group comprises only the two metal-rich aubrites, Mount Egerton and Larned. Their pyroxenes display striking light-REE enrichments $\left(\mathrm{La}_{\mathrm{n}} / \mathrm{Sm}_{\mathrm{n}}=2.44-5.11\right)$. These two groups are easily distinguished using $\mathrm{Th} / \mathrm{Sm}$ ratios which are less sensitive to traces of plagioclases (Fig. 5). In addition, the Mount Egerton pyroxenes display higher $\mathrm{Eu} / \mathrm{Eu}^{*}$ ratios than the other aubritic pyroxenes. The higher $\mathrm{Eu} / \mathrm{Eu}^{*}$ and $\mathrm{Sr} / \mathrm{Sm}$ ratios shown by our Larned sample compared to Mount Egerton, are consistent with traces of plagioclases. and to determine the composition of their silicate fractions, we leached aliquots of the powdered matrices in hot $\mathrm{HCl}$, following the same procedure as Barrat et al. (2014) for enstatite chondrites (see above). The results are given in Table 2 for the residues and in Table 3 for the leachates. In addition, 
we analyzed the leachates obtained with some pyroxene fractions. The results obtained on the two unusual aubrites Aubres and Bishopville will be described at the end of this section.

Oldhamites in aubrites display a variety of REE patterns, even in a given meteorite (Floss et al., 1990, Floss and Crozaz, 1993; Wheelock et al., 1994; McCoy and Dickinson, 2001). Unlike previous in-situ analyses, our procedure provides only a picture of the average sulfide in any given sample. The trace element abundances of the leachates are consistent with literature data. Indeed, the REE patterns of many leachates, those displaying marked negative Eu anomalies, are similar to those obtained in large oldhamite crystals from Norton County or Bustee (e.g., Floss and Crozaz, 1993; Wheelock et al., 1994), and could represent the most common oldhamite signature in aubrites (Fig. 6). Moreover, they display negative $\mathrm{Y}$ anomalies $\left(\mathrm{Y}_{\mathrm{n}} / \mathrm{Ho}_{\mathrm{n}}=0.47-0.90\right)$ and resemble the REE patterns of EL6 oldhamites (Floss and Crozaz, 1993; Barrat et al., 2014). Notice that the leachates obtained with the pyroxene fractions sample the sulfides included into the pyroxenes, which are not necessarily representative of those of the whole meteorites. Thus, it is not surprising that their signatures are sometimes distinctive: the patterns of the leachates obtained with the Khor Temiki, Norton County (C), and Pesyanoe pyroxenes are similar to those of large oldhamite grains analyzed by Wheelock et al. (1994) and are certainly controlled by this type of oldhamite, contrary to those obtained with the Aubres pyroxene $\mathrm{A} 1$, which displays large positive $\mathrm{Eu}, \mathrm{Y}$ and $\mathrm{Yb}$ anomalies, and with the Norton $\mathrm{Co}$ pyroxenes A and B that show only minor negative Eu anomalies, no $\mathrm{Y}$ anomalies and marked lightREE enrichments. The diversity of the oldhamite signatures, or contributions from other sulfides (alabandite...) can perfectly explain the shape of these patterns.

Residues obtained from matrices exhibit much lower lithophile trace element abundances than their corresponding unleached fractions (Table 2), confirming that sulfides are carriers for most of the elements determined here. All these residues are heavy-REE enriched $\left(\mathrm{Gd}_{\mathrm{n}} / \mathrm{Lu}_{\mathrm{n}}=0.16-0.69\right)$, display variable $\mathrm{Y}$ anomalies $\left(\mathrm{Y}_{\mathrm{n}} / \mathrm{Ho}_{\mathrm{n}}=0.78-1.76\right)$, and variable Eu anomalies $(\mathrm{Eu} / \mathrm{Eu} *=0.09-24.2)$ depending on the amount of plagioclase they contained. None of these residues display marked light-REE enrichment unlike the Larned or Mount Egerton pyroxenes.

The residue obtained with the Bishopville fraction displays the same distinctive La enrichment as the unleached powder (Fig. 1), and the largest positive Eu anomaly $\left(\mathrm{Eu} / \mathrm{Eu}^{*}=24.2\right)$ obtained in this 
study, in agreement with the high proportion of plagioclase in this meteorite. A La and Ce enrichment was previously obtained on plagioclase from the same meteorite [see Figure 2 in Floss et al. (1990)], but this phase is too light-REE poor $(\mathrm{La}<0.2 \mathrm{x} \mathrm{CI})$ to explain the La enrichment in the unleached fraction. Moreover, the REE pattern of the leachate displays a similar La-spike (Fig. 6). We conclude that this feature is shared by the silicates and some of the sulfides in this meteorite.

The residue obtained with the Aubres matrix sample (Fig. 2) exhibits a positive Eu anomaly $\left(\mathrm{Eu} / \mathrm{Eu}^{*}=2.96\right)$ suggesting the occurrence of plagioclase in the fraction, and a positive $\mathrm{Y}$ anomaly like many pyroxene fractions or other residues $\left(\mathrm{Y}_{\mathrm{n}} / \mathrm{Ho}_{\mathrm{n}}=1.46\right)$. However, it does not show a $\mathrm{Tb}$ anomaly $\left(\mathrm{Tb} / \mathrm{Tb}^{*}=0.96\right)$, in contrast to the leachate, which displays a flat REE pattern with a positive $\mathrm{Tb}$ anomaly $\left(\mathrm{Tb} / \mathrm{Tb}^{*}=1.61\right)$ comparable to that of the unleached fraction, and marked negative $\mathrm{Y}$ and $\mathrm{Eu}$ anomalies $\left(\mathrm{Y}_{\mathrm{n}} / \mathrm{Ho}_{\mathrm{n}}=0.84, \mathrm{Eu} / \mathrm{Eu}^{*}=0.39\right)$. Thus, the $\mathrm{Tb}$ positive anomaly is clearly carried by a leachable phase/component.

\subsection{Oxygen isotopes}

Previous studies (Clayton and Mayeda, 1996; Newton et al., 2000; Miura et al., 2006; Keil et al., 2011) indicated that the oxygen isotopic composition of aubrites straddled the terrestrial fractionation line (Fig. 7) and displayed a relatively narrow range of variability with respect to $\Delta^{17} \mathrm{O}( \pm$ 0.1\%o). Cumberland Falls is a notable exception, showing a significantly more positive $\Delta^{17} \mathrm{O}$ composition than the other aubrites, due to the presence of debris from an unusual ordinary chondrite (e.g., Neal and Lipschutz, 1981; Lipschutz et al., 1988).

We have analyzed 12 aubrites (including 8 falls) and a chondritic clast from Cumberland Falls (Table 4, Figs 7, 8). Compared to previous analyses, the falls show a much more restricted range of linearized $\Delta^{17} \mathrm{O}$ values, with an average $=+0.009 \pm 0.010 \%$ o $(2 \sigma)$. In comparison, Newton et al. (2000) obtained an average $\Delta \Delta^{17} \mathrm{O}$ value for the same aubrite falls of $-0.043 \pm 0.096 \%$ o $(2 \sigma)$ and Miura et al. (2006) obtained an average $\Delta^{17} \mathrm{O}$ value of $+0.015 \pm 0.058 \%$ (2 $\left.\sigma\right)$ using a more restricted set of aubrites (all values calculated using a $\lambda=0.5247$ ). In the case of the Newton et al. (2000) study, which was also undertaken at the Open University, the lower levels of precision reflect the fact that the data 
were obtained using an earlier generation of laser system and less refined analytical protocols than those employed here. In terms of $\delta^{18} \mathrm{O}$, the data form a relatively tight array with values ranging from +5.2 to $+5.7 \%$. Bishopville has the heaviest $\delta^{18} \mathrm{O}$ value measured among the falls, and this almost certainly is a reflection of the sample's high plagioclase content. The O isotopic compositions of the two Antarctic samples after EATG treatment are analytically indistinguishable from the falls. The other finds are Mount Egerton and Larned, the two light-REE enriched aubrites. A Mount Egerton pyroxene fraction displays the very same oxygen isotopic composition as the aubritic falls. Both the untreated and the acid-leached fractions of Larned are somewhat heavier in terms of their $\Delta^{17} \mathrm{O}$ compositions than the aubritic falls. Larned is composed of highly shocked clasts set in a matrix rich in metal and Fe-sulfide (Irving et al., 2010), suggesting a possible projectile contribution. aubrite ALHA 78113 were previously determined by Clayton and Mayeda (in Verkouteren and Lipschutz, 1983) and Clayton et al. (1991). Our new analysis of one of these clasts is in the range of the previous data, but with a lower $\Delta^{17} \mathrm{O}$ value (Fig. 7).

\section{Discussion}

\subsection{Evidence for early, large-scale melting on the aubrite parent body.}

318 the aubrite falls. Their $\Delta^{17} \mathrm{O}$ ratios define a narrow range, from -0.001 to $+0.017 \%$. This homogeneity strongly suggests that these aubrites formed either from primitive materials sharing the same isotopic composition, or alternatively from a single body that was initially heterogeneous and subsequently experienced a high level of $\mathrm{O}$ isotope homogenization. The first possibility is unlikely because enstatite chondrites, which are the best analogs for the parent materials to aubrites, have much more heterogeneous $\Delta^{17} \mathrm{O}$ values [from -0.32 to $+0.16 \%$ for twelve EH3-6 chondrites, and from -0.11 to $+0.07 \%$ for sixteen EL3-6 chondrites taken into account only falls and $\mathrm{HCl}$ treated finds (Newton et

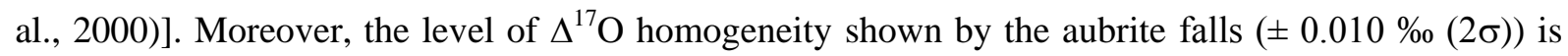


equivalent to that of other bodies which show evidence for an early global stage of melting i.e., 4Vesta $[ \pm 0.014 \%$ \% $(2 \sigma)$, Greenwood et al., 2005, 2014; Scott et al., 2009], the angrite-parent body [ \pm $0.014 \%(2 \sigma)$, Greenwood et al., 2005], the main-group pallasites parent body $[ \pm 0.016 \%(2 \sigma)$, Greenwood et al., 2006, 2015], the Moon [ $< \pm 0.021 \%(2 \sigma)$, Spicuzza et al., 2007; Hallis et al., 2010; Herwartz et al., 2014; Young et al., 2016] and Mars [ $\pm 0.026 \%$ (2 $\sigma)$, Franchi et al., 1999]. Thus, the narrow range of oxygen isotope compositions displayed by the aubrites indicates that some form of isotopic homogenization took place on their parent body. It is generally accepted that early-formed asteroids experienced extensive melting, possibly as high as 70\% (e.g. McCoy et al. 2006), which would have resulted in high-levels of oxygen isotope homogenization (Clayton and Mayeda, 1996;

Greenwood et al., 2005). The possibility that the aubrite parent body experienced such large-scale, magma ocean-style, melting was first proposed by Taylor et al. (1993). However, the presence of magma oceans on asteroids, such as the aubrite parent body, is not universally accepted (e.g.Wilson and Keil, 2012, 2016; Wasson, 2013). Most models for early asteroidal melting invoke ${ }^{26} \mathrm{Al}$ as a heat source (Ghosh and McSween, 1998; Hevey and Sander, 2006), which Wasson (2013) argues was not present in the precursor chondrites at sufficient levels to form magma oceans. Wilson and Keil (2012, 2016), based on modeling calculations, also argue against the existence of magma oceans on any differentiated asteroids the size of 4 Vesta or smaller. As an alternative to heating by short-lived radionuclides, Wasson (2013) suggests that impact heating would have caused extensive melting. While Keil et al. (1997) have argued against such a process, recent modelling studies provide support for this possibility provided the impacting bodies were relatively porous (Davison et al., 2010). However, whether as the result of radiogenic heating, or impact-related processes, the oxygen isotope results presented here provide strong evidence that the aubrite parent body experienced extensive melting that was sufficient to cause high-levels of oxygen isotopic homogenization.

The two Antarctic finds display treated $\Delta^{17} \mathrm{O}$ values identical or analytically indistinguishable to the compositions of the falls. The results obtained on the two anomalous aubrites Mount Egerton and Larned are ambiguous. The $\mathrm{O}$ isotopic composition of Mount Egerton is identical to the aubrite falls. However, Larned appears distinct, but this meteorite contains possible traces of an ordinary 
chondrite projectile. The connection of these two anomalous samples with the main-group aubrites is discussed below (section 4.4).

\subsection{Petrology of aubrites: trace element constraints.}

\subsubsection{Lithophile trace element inventory in main-group aubrites.}

It is well established that the REE budget of aubrites is largely governed by sulfides, notably oldhamite (Floss et al., 1990; Floss and Crozaz, 1993; Wheelock et al., 1994; Lodders, 1996; Dickinson and McCoy, 1997, McCoy and Dickinson, 2001), but their contribution to the other lithophile elements is not known at present. Of course, the trace element abundances of the various sulfides could be determined in situ by ion-probe or by laser-ICP-MS, but it would require a large number of analyses. As in the case of the enstatite chondrites (Barrat et al., 2014), an estimation of the contribution of sulfides to the trace element inventory of aubrites can be easily obtained using our leaching experiments. The residues after leaching (=silicate fraction) provide a complementary picture to the sulfide and metal contributions in aubrites. The behavior of a given element can be deduced from the ratio of the concentrations in the residues and in the whole rocks $\left(\mathrm{C}_{\text {residue }} / \mathrm{C}_{\text {whole rock }}\right)$. Because aubrites contain essentially silicates, these ratios range from 0 for strictly chalcophile (or siderophile) elements to $\geq 1$ for strictly lithophile elements $\left(C_{\text {metal }}=C_{\text {sulfides }}=0\right)$. None of the elements we have analyzed display perfectly lithophile behavior (Fig. 9a). Among them, Rb, Ba, Sr, and Sc display generally the highest $C_{\text {residue }} / C_{\text {whole rock }}$ ratios indicating that silicates are the main carriers for these elements. Peña Blanca Spring shows the lowest $\mathrm{C}_{\text {residue }} / \mathrm{C}_{\text {whole rock }}$ ratios for Ba and Sc suggesting the involvement of particular sulfide(s) in this aubrite. No Ba-bearing sulfide is known in aubrites at rock ratio $>1$ signifying that its sulfides are devoid of this element. The other samples show much lower $\mathrm{Nb}_{\text {residue }} / \mathrm{Nb}_{\text {whole rock }}$ ratios (0.49-0.86), suggesting the involvement of a Nb-bearing Fe sulfide, or present. Niningerite is a Sc carrier (e.g., Frasier et al., 1985), and could potentially explain the low Sc abundance of the Peña Blanca Spring residue. However, this phase is uncommon in aubrites, and has only been observed in Bustee (McCoy, 1998). Bustee is the sole sample displaying a $\mathrm{Nb}_{\text {residue }} / \mathrm{Nb}_{\text {whole }}$ perhaps traces of $\mathrm{Nb}$ in metal, as previously proposed for EL6 (Barrat et al., 2014). All the other 
elements including REEs, $\mathrm{Zr}$, Hf, Ti, $\mathrm{V}$ and $\mathrm{Mn}$ display $\mathrm{C}_{\text {residue }} / \mathrm{C}_{\text {whole rock }}$ ratios $<0.7$, which indicate strong chalcophile behavior, in agreement with the occurrence of oldhamite, Ti-rich troilite, and ferroan alabandite.

The contribution of the sulfides to the trace element budgets can be directly deduced from the $\mathrm{C}_{\text {residue }} / \mathrm{C}_{\text {whole rock }}$ ratios based on simple mass balance calculations:

where $\mathrm{X}_{\text {residue }}, \mathrm{X}_{\text {sulfides }}$, and $\mathrm{X}_{\text {metal }}$ are respectively the weight proportions of silicates, sulfides, and metal in the whole rock. We can reasonably neglect the metallic Fe,Ni contribution in aubrites: metal is devoid of lithophile elements, and is rare here $(\ll<1$ vol\%, e.g., Keil, 2010). For a given element present in both silicates and sulfides, the contribution of sulfides is directly obtained from the following equation:

$$
\mathrm{X}_{\text {sulfides }} \cdot \mathrm{C}_{\text {sulfides }} / \mathrm{C}_{\text {whole rock }} \approx 1-\mathrm{X}_{\text {residue }} \cdot \mathrm{C}_{\text {residue }} / \mathrm{C}_{\text {whole rock }}
$$


Wheelock et al., 1994; Newsom et al., 1996), and some of the unusual trace element ratios, as exemplified by the occasional low Y/Ho ratios (Fig. 1).

The unusual positive $\mathrm{Tb}$ anomaly displayed by one of our samples of Aubres merits further discussion (Fig. 2). To our knowledge, large positive Tb anomalies have never been described before in extraterrestrial materials and the discovery of such an anomaly in Aubres was astonishing. One may suggest that our sample has been contaminated during recovery, handling, storage or processing. However, possible natural contaminants that could be introduced into the sample (e.g., dust, soil...) are devoid of $\mathrm{Tb}$ anomalies because $\mathrm{Tb}$ is not decoupled from other trivalent REEs by terrestrial processes. If a continental contaminant was introduced into Aubres, no $\mathrm{Tb}$ anomaly would have been detected. Alternatively, a Tb pollution could be envisaged if a solution of pure $\mathrm{Tb}$ was prepared or handled in the Natural History Museum or in our clean laboratory during the dissolution and preparation of the samples, but this was not the case. We conclude that the positive $\mathrm{Tb}$ anomaly displayed by the sample of Aubres provided by the Natural History Museum (A2) is pristine. Because the leachate prepared using this sample displays a similar $\mathrm{Tb}$ anomaly, and because the residue is devoid of Tb anomaly, we conclude that this anomaly was hosted by a phase which was leached and removed by hot $\mathrm{HCl}$. This phase is not identified at present, but could be an unusual sulfide or another leachable phase (perhaps a nitride, as suggested by the anonymous reviewer). The positive $\mathrm{Tb}$ anomaly shown by the leachate suggests that a fraction of $\mathrm{Tb}$ could be in a distinct valence state compared to its neighbor REEs. Laser-ICP-MS analyses and additional studies of the accessory phases in Aubres, are needed to identify this mineral.

\subsubsection{What can we infer about aubritic parental melts from trace element abundances?}

The parental melts of aubrites are unknown, and constraining their compositions is one of the main challenges for understanding the petrology of these rocks.

If, as discussed in section 4.1, aubrites formed during the cooling of a magma ocean, they would have crystallized from melts that were derived from essentially the same parental magma. At first glance, this possibility seems in agreement with the REE abundances of the whole rocks (Fig. 1a). Indeed, it can be assumed that, at least to first order, the composition of a nearly 
monomineralic orthopyroxenite like an aubrite, can be explained by a two-component model with mainly cumulus enstatite and a small proportion of trapped melt. This trapped melt is much richer in REEs than pyroxenes (e.g., van Kan Parker et al., 2010). Consequently, a small fraction of trapped melt will easily obliterate the REE features of the pyroxenes in such a mixture. Seen in this light, the rather limited variability in the shapes of the REE patterns of the whole rocks suggests the involvement of a similar trapped melt component characterized by flat REE pattern, in agreement with the magma ocean hypothesis. Moreover, the REE pattern variability that we do see, could be explained by the small size of the analyzed samples (representativeness of the samples), and diverse contributions from accessory phases (plagioclases, sulfides including oldhamite), which can account for the Eu and $\mathrm{Y}$ anomalies, and possibly the Tb anomaly displayed by Aubres. composition of aubritic melts? The compositions of the melts that were parental to extraterrestrial cumulates are frequently estimated using the trace element abundances of their minerals and relevant partition coefficients. This approach should certainly provide correct results, as long as the composition of these phases has not been redistributed by post-crystallization processes and when trapped melts are not involved. Unfortunately, aubrites before brecciation were slowly cooled pyroxenites, and their pyroxenes commonly display diopsidic blebs or exsolutions (e.g., Okada et al., 1988). The trace element abundances of the phases in these rocks were possibly affected by subsolidus exchanges. Treiman (1996) and Pun et al. (1997) have shown that such exchanges can significantly alter trace element distributions, notably the light REE abundances of pyroxenes and plagioclases. Therefore, the trace element abundances of the parent melts estimated directly from the equilibrium partition coefficients are not necessarily reliable, especially if the rock contains REE-rich phases or if trapped melts were involved. This question has been extensively discussed for cumulates where phosphates controlled the budget of light-REEs. In some cases, useful constraints on the REE abundances of the parental melts can be inferred (e.g., Barrat, 2004; Barrat and Bollinger, 2010).

460 However, the problem for aubrites is much more complex because we do not know the composition of 461 their parental melts (i.e., if they were "basaltic" or more $\mathrm{SiO}_{2}$-rich, the proportions of the various phases they crystallized etc.), and the available experimental partition coefficients for the REE-rich 
sulfides are still limited. Lodders (1996) and Dickinson and McCoy (1997) have determined partition coefficients between oldhamite and melt around 0.3-0.4 for La and between 0.7 to 3 for $\mathrm{Yb}$ at 1200 $1300^{\circ} \mathrm{C}$, which are very different from the values inferred from the abundances of the phases in aubrites (Dickinson and McCoy, 1997 and references therein). For calculation purposes, we used the abundances we obtained for three enstatite-sulfide pairs (Khor Temiki, Norton County (C) and Pesyanoe), and the partition coefficients of enstatite obtained by Van Kan Parker et al. (2010) in order to estimate the partition coefficients of oldhamite in aubrites (Fig. 10). Measured sulfide/enstatite ratios for REEs are high (>400), and consequently large $\mathrm{D}_{\mathrm{CaS} / \text { melt }}$ values are calculated, but with considerable variation between samples. We find that $\mathrm{Sm}, \mathrm{Gd}$ and the heavy REEs are much more compatible than the light REEs $\left(\mathrm{D}_{\mathrm{Sm}} / \mathrm{D}_{\mathrm{La}}=20-33\right)$, and $\mathrm{Y}$ less compatible than $\mathrm{Ho}\left(\mathrm{D}_{\mathrm{Y}} / \mathrm{D}_{\mathrm{Ho}}=0.4-0.5\right)$. The partition coefficient patterns display deep negative Eu anomalies, but $\mathrm{D}_{\mathrm{Eu}}$ was approximated using the experimental partition coefficient of Sr for enstatite, because Van Kan Parker et al. (2010) did not measure this coefficient for Eu and carried out their experiments in air, i.e. in oxidizing conditions. But, even if $D_{S r}$ was not exactly equivalent to $D_{E u}$, it is obvious that $E u$ is much less compatible than Sm and Gd. The oldhamite partition coefficients calculated from the sulfide/enstatite pairs are radically different from the experimental results. The calculated Ds are much more compatible than the experimental ones. Three hypotheses can account for such a mismatch: 1/ oldhamites in aubrites are not in equilibrium with the silicates; $2 /$ trace elements have been strongly redistributed by postcrystallization processes; and 3/ the experimental partition coefficients are not correct or not appropriate in the case of aubrites.

At least some of the aubritic oldhamites unambiguously formed during the crystallization of the parental melt (e.g., Wheelock et al., 1994; McCoy, 1998), and were almost certainly in equilibrium with it at that time. However, a nebular origin for some grains has been proposed, and if correct, could potentially account for the mismatch between the experimental and calculated partition coefficients. Some of the REE distributions in aubritic oldhamites and unequilibrated enstatite chondrites are similar. Because pure oldhamite melts at temperatures $>2300^{\circ} \mathrm{C}$, much higher than magmatic temperatures, it was suggested that some aubritic oldhamites could be relict phases from the enstatite chondrite-like precursor material (e.g., Floss et al., 1990; Floss and Crozaz, 1993; Lodders, 1996). 

independent isotopic fractionations in S (Rai et al., 2005) and large variations in neutron fluences recorded by Sm and Gd isotopic compositions (Hidaka et al., 2012), possibly associated with sulfides. On the other hand, McCoy et al. (1999) demonstrated that all the sulfides, including oldhamite, within an enstatite chondrite melt completely before the onset of silicate melting $\left(\mathrm{T}=1000^{\circ} \mathrm{C}\right)$. Thus, in agreement with these authors, the oldhamites in aubrites cannot be relict phases and are necessarily magmatic in origin. Moreover, the mass independent isotopic fractionations of $\mathrm{S}$ are more likely explained by a contribution of $\mathrm{FeCl}_{2}$ containing excesses of ${ }^{36} \mathrm{~S}$ due to the decay of ${ }^{36} \mathrm{Cl}$ to the leached oldhamites (Defouilloy et al., 2016). Additional work is necessary to explain the high fluences recorded by some Norton County oldhamites, but at present a magmatic origin for oldhamite in aubrites is accepted by most authors.

The effects of subsolidus reequilibration and of a trapped melt component are difficult to evaluate. They are dependent on the equilibrium partition coefficients and mass proportions of all cumulus phases, the mode and the composition of the phases in the fully equilibrated rock, and the mass fraction of the trapped melt (Barrat, 2004). To illustrate these effects, we have calculated the "apparent partition coefficients" (in other words the ratios of the concentrations of a given element in oldhamite divided by the concentration of the same element in the parental melt) after subsolidus reequilibration using the equations given by Barrat (2004). For calculation purposes, we assume a cumulate containing only cumulus enstatite and variable proportions of a hypothetical trapped melt that crystallized $90 \%$ enstatite, $7 \%$ plagioclase, and 3\% oldhamite. This example shows that subsolidus reequilibration and trapped melt effects are able to generate for any given cumulate a large range of apparent partition coefficients for oldhamite, and for other phases as well (Fig. 11). It demonstrates that attempting to deduce the shape of the REE pattern of aubritic parental melts using the trace element abundances of the various constituent phases is problematic. Furthermore, although trapped melt effects are capable of enhancing significantly the apparent partition coefficients of 516 oldhamite, they are unable to explain the huge discrepancy between the apparent coefficients as 517 estimated from the three sulfide-enstatite pairs, compared to the experimentally-derived partition coefficients for oldhamite. We suspect that the experimental oldhamite partition coefficients are not 
suitable for aubrites. Alternatively, equilibration at metamorphic conditions (without melts) generates more extreme redistributions of REEs between oldhamite and enstatite than assumed in our calculations. These two possibilities are not necessarily exclusive.

Thus, it is not yet possible to confirm that the diversity of the trace element abundances in the pyroxenes and the oldhamites is linked to the variability of the aubritic melts. The possible initial diversity of the REE patterns of the phases was certainly amplified by trapped melt effects and subsolidus processes. Partition coefficients for oldhamite appropriate for the aubrites are clearly needed to discuss further this question.

\subsection{Are Mount Egerton and Larned from the same parent body as the main-group aubrites?}

The oxygen isotopic composition of Mount Egerton is identical to the aubrite falls average and this observation could be seen as a strong argument in favor of their derivation from the same parent body. The isotopic composition of Larned deviates slightly from the aubrite falls average and we emphasize that this difference could be explained by a projectile contribution to this breccia. However, these two samples display trace element abundances that contrast strongly with those of the maingroup aubrites. REE-rich sulfides have not yet been observed in either of these meteorites. Moreover, Mount Egerton consists of crystals of enstatite, which are sometimes very large (see figures 2 and 3 in McCall, 1965), enclosed in metal. Subsolidus reequilibration or the influence of a trapped melt cannot definitively be invoked here: the light-REE enrichments displayed by the enstatite crystals in this meteorite are certainly a pristine feature, a conclusion that seems probable for Larned too. These lightREE enriched pyroxenes were necessarily in equilibrium with melts displaying much more pronounced light REE-enrichments. Were these melts formed in the same magmatic system as the main-group aubrites? We suggested above that main-group aubrites may have crystallized in a magma ocean, from melts displaying rather flat REE patterns. The main phases extracted from these melts were chiefly low-Ca pyroxenes, plagioclase, olivine and certainly small amounts of various sulfides including oldhamite and alabandite. Due to the lack of experimental data, it is at present impossible to 
model accurately the liquid line of descent of a magma ocean in highly reducing conditions, and to

calculate precisely the trace element abundances of the residual melts. However, as a consequence of

the extraction of plagioclase, the residual melts were certainly characterized by deep negative Eu anomalies. Because light REEs are incompatible during the crystallization of olivine, pyroxene and plagioclase, these phases will have no impact on the distribution of the light REEs in the residual melts. However, the crystallization of REE-bearing sulfides could potentially fractionate the light REE abundances. If the available experimental partition coefficients are correct (see fig. 10b), the involvement of a few percent of oldhamite would only have a moderate impact on the light REE behavior, and the production of residual melts with a marked light-REE enrichment seems improbable or at best very difficult. On the other hand, if the experimental data are inappropriate here, and if REE are compatible during the crystallization of oldhamite, such a possibility cannot be excluded. In any case, Mount Egerton pyroxenes did not form from such evolved melts because their Eu anomalies are much less pronounced than those displayed by the pyroxenes of the other aubrites. This evidence makes a direct link with the main-group aubrites at best extremely difficult, if not totally improbable.

The differences between Mount Egerton and the main-group aubrites extend to siderophile

trace elements in metal. In contrast to the metal contained by aubrites that display Os, Ir, and Pt depletions, the metal grains in Mount Egerton displays mostly unfractionated siderophile element distributions akin to EL chondrite metal (van Acken et al., 2012), to the Horse Creek iron (Wolf et al., 1983; Casanova et al., 1993; Humayun, 2010), and possibly to the metal found in the NWA 2526 enstatite achondrite (van Acken et al., 2012). Moreover, Mount Egerton metal and Horse Creek display similar $\mathrm{W}$ isotopic compositions $\left(\varepsilon^{182} \mathrm{~W} \approx+0.5\right)$, which are much less radiogenic than metals from Khor Temiki, Norton County and Peña Blanca Spring $\left(\varepsilon^{182} \mathrm{~W} \approx+3.3\right.$ to +8 , Petitat et al., 2008). A possible link between Horse Creek and Mount Egerton was proposed by Watters and Prinz (1980). The literature data and our new analyses suggest that in addition to these two meteorites, Larned and possibly NWA 2526 could also be related. boundary of the aubrite parent body (Watters and Prinz, 1980). However, this hypothesis is 
inconsistent with the unfractionated composition of the metal (e.g., Brett and Keil, 1986; van Acken et al., 2012). More recently, Rubin (2015) discussed a possible link between the Shallowater enstatite achondrite and Mount Egerton. He proposed that Shallowater formed in a porous rubble pile body, from an impact melt deeply buried beneath multi-kilometer thick layers of compressed target material. He emphasized that such bodies are likely to contain unseparated metal and silicate, and that Mount Egerton could have formed similarly. In addition, he noted that like Mount Egerton, Shallowater is unbrecciated, displays very large enstatite crystals (up to $4 \mathrm{~cm}$ ), and has the same cosmic-ray exposure age $(\approx 27 \mathrm{Ma}$, Lorenzetti et al., 2007), but these convergences could just be fortuitous. Indeed, it is worth noting that unlike Mount Egerton, Shallowater metal has a $\varepsilon^{182} \mathrm{~W} \approx-3$, similar to metal in ordinary chondrites (Petitat et al., 2008).

Whatever the link with Shallowater might be, the genesis of Mount Egerton remains uncertain. It appears more likely that Mount Egerton and Larned are samples of a distinct parent body unrelated to main-group aubrites, despite their very similar $\Delta^{17} \mathrm{O}$ values.

\section{Conclusions}

1. Two distinct groups of aubrites can be defined using lithophile trace elements abundances: 1) the "normal" or main-group aubrites, and 2) Mount Egerton and Larned. The main-group aubrites display rather flat or slightly light-REE depleted REE patterns with variable Eu and Y anomalies depending on the nature of the accessory phases involved (plagioclase and sulfides). The trace element distributions of their pyroxenes show more diversity, particularly variable light REE depletions, marked negative Eu anomalies, and variable Y/Ho ratios. Two of the main-group aubrites show unusual features. Bishopville displays an unusual positive La anomaly whose origin is not understood. One of the Aubres samples we analyzed exhibits a positive Tb anomaly that is probably the fingerprint of an accessory phase and suggests that Tb occurs in this rock, at least partly at a distinct valence state, possibly $2+$. Mount Egerton and Larned are clearly distinct. The Mount Egerton enstatites and the silicate fraction prepared with Larned display marked light-REE enrichments. The differences extend to other trace element ratios like $\mathrm{Th} / \mathrm{Sm}$. In addition, Mount 
Egerton pyroxenes have much less pronounced negative Eu anomalies than pyroxenes from the main-group aubrites.

2. The contributions of the sulfides to the lithophile element budgets of the main-group aubrites

604 are important. Sulfides contain in most cases about $50 \%$ or more of the REEs, the actinides, Ti, V, and $\mathrm{Mn}$ of the whole rocks. Among the elements we have analyzed, those displaying the strongest lithophile behaviors are $\mathrm{Rb}, \mathrm{Ba}, \mathrm{Sr}$ and $\mathrm{Sc}$.

3. Our oxygen isotope data for main-group aubrites are consistent with their derivation from a single parent body. The homogeneity of the $\Delta^{17} \mathrm{O}$ values determined on the fall samples $\left(\Delta^{17} \mathrm{O}=\right.$ $+0.009 \pm 0.010 \%(2 \sigma)$, strongly suggests that aubrite parent body underwent an early phase of global-scale melting, which may have generated a magma ocean. This interpretation is at first glance in agreement with the rather limited variability of the REE patterns of whole rock samples of these aubrites that possibly suggests that their parental melts displayed rather flat REE patterns. However, the trace element concentrations of their constituent phases cannot be used to discuss this hypothesis. Redistributions of trace elements by subsolidus processes and trapped melt effects could explain the diversity of the REE patterns displayed by oldhamites and pyroxenes.

4. The marked light-REE enrichments displayed by Mount Egerton and Larned demonstrate that they are unrelated to the main-group aubrites, despite similar $\mathrm{O}$ isotopic compositions. It is more likely that they originate from a distinct parent body.

\section{Acknowledgements}

Most of the samples analyzed during the course of this study were kindly provided by the National History Museum, London, the Vernadsky Institute, Moscow, the Institute for Meteoritics, Albuquerque, the Muséum National d'Histoire Naturelle de Paris (MNHN), the NASA meteorite working group and Don Stimpson. US Antarctic meteorite samples are recovered by the Antarctic search for Meteorites (ANSMET) program which has been funded by NSF and NASA, and characterized and curated in the department of Mineral Sciences of the Smithsonian Institution and Astromaterials Curation Office at NASA Johnson Space Center. We thank Anders Meibom for the editorial handling, Christine Floss, an anonymous reviewer for constructive comments, and Pascale Barrat for her help. We gratefully acknowledge the Programme National de Planétologie (CNRSINSU) for financial support. Oxygen isotope studies at the Open University are funded through a 

Sciences. This research has made use of NASA's Astrophysics Data System Abstract Service. The work of K.K. was supported in part by NASA grant NAG5-12882 (A. Krot, P.I.). This is Hawai'i Institute of Geophysics and Planetology publication No. XXX and School of Ocean and Earth Science and Technology publication No.YYYY.

Barrat J.A. (2004) Determination of the parental magmas of HED cumulates: The effects of interstitial melts. Meteoritics Planet. Sci. 39, 1767-1779.

Barrat J.A. and Bollinger C. (2010) Geochemistry of the martian meteorite ALH84001, revisited. Meteoritics Planet. Sci. 45, 495-512.

Barrat J.A., Keller F., Amossé J., Taylor R.N., Nesbitt R.W., Hirata T. (1996) Determination of rare earth elements in sixteen silicate reference samples by ICP-MS after Tm addition and ion exchange separation. Geostandards Newsletter 20, 1, 133-140.

Barrat J.A., Zanda B., Moynier F., Bollinger C., Liorzou C., and Bayon G. (2012) Geochemistry of CI chondrites: Major and trace elements, and $\mathrm{Cu}$ and $\mathrm{Zn}$ isotopes. Geochim. Cosmochim. Acta 83, 79-92.

Barrat J.A., Zanda B., Jambon A., Bollinger C. (2014) The lithophile trace elements in enstatite chondrites. Geochim. Cosmochim. Acta. 128, 71-94.

Barrat J.A., Dauphas N., Gillet P., Bollinger C., Etoubleau J., Bischoff A., Yamaguchi A. (2016) Evidence from Tm anomalies for non-CI refractory lithophile element proportions in terrestrial planets and achondrites. Geochim. Cosmochim. Acta, 176, 1-17.

Brett R. and Keil K. (1986) Enstatite chondrites and enstatite achondrites (aubrites) were not derived from the same parent body. Earth Planet. Sci. Lett. 81, 1-6.

Casanova I., Keil K., Newsom H.E. (1993) Composition of metal in aubrites: constraints on core formation. Geochim. Cosmochim. Acta 57, 675-682.

Clayton, R.N., Mayeda, T.K. (1996) Oxygen isotope studies of achondrites. Geochim. Cosmochim. Acta 69, 1999-2017.

Clayton, R.N., Mayeda, T.K., Goswani J.N., Olsen E.J. (1991) Oxygen isotope studies of ordinary chondrites. Geochim. Cosmochim. Acta 55, 2317-2337.

Dauphas N, Pourmand A. (2015) Thulium anomalies and rare earth element patterns in meteorites and Earth: Nebular fractionation and the nugget effect. Geochim. Cosmochim. Acta 163, 234-261.

Davison T.M., Collins G.S., Ciesla F.J. (2010) Numerical modelling of heating porous planetesimals collisions. Icarus 208, 468-481.

Defouilloy C., Cartigny P., Assayag N., Moynier F., Barrat J.A. (2016) High-precision sulfur isotope $\left({ }^{32} \mathrm{~S},{ }^{33} \mathrm{~S},{ }^{34} \mathrm{~S},{ }^{36} \mathrm{~S}\right)$ composition of enstatite meteorites and implications for the formation and evolution of their parent bodies. Geochim. Cosmochim. Acta. 172, 393-409.

Dickinson T.L., McCoy T. (1997) Experimental rare-earth-element partitioning in oldhamite: implications for the igneous origin of aubritic oldhamite. Meteoritics Planet. Sci. 32, 395-412.

Easton A.J. (1985) Seven new bulk chemical analyses of aubrites. Meteoritics 20, 571-573.

Franchi I. A., Wright I. P., Sexton A. S., and Pillinger C. T. (1999) The oxygen isotopic composition of Earth and Mars. Meteoritics Planetary Science 34, 657-661. 
Frazier R. M. and Boynton W. V. (1985) Rare earth and other elements in components in the Abee enstatite chondrite. Meteoritics 20, 197-218.

Floss C. and Crozaz G. (1993) Heterogeneous REE patterns in oldhamite from the aubrites: their nature and origin. Geochim. Cosmochim. Acta 57, 4039-4057.

Floss, C., Strait, M.M., Crozaz, G. (1990) Rare earth elements and the petrogenesis of aubrites. Geochim. Cosmochim. Acta 54, 3553-3558.

Fogel R.A. (1998) High sulfur-low iron silicate melts: Low oxygen fugacity phenomena of importance to aubrite formation. Meteoritics Planetary Science 33, A52.

Fogel R.A. (2005) Aubrite basalt vitrophyres: The missing basaltic component and high-sulfur silicate melts. Geochim. Cosmochim. Acta 69, 1633-1648.

Ghosh A., McSween H.Y. Jr. (1998) A thermal model for the differentiation of asteroid 4 Vesta based on radiogenic heating. Icarus 134, 187-206.

Greenwood R.C., Franchi I.A., Jambon A. and Buchanan P.C. (2005) Widespread magma oceans on asteroidal bodies in the early solar system. Nature $\mathbf{4 3 5}, 916-918$.

Greenwood R.C., Franchi I.A., Jambon A., Barrat J.A., Burbine T.H. (2006) Oxygen isotope variation in stony-iron meteorites. Science 313, 1763-1765.

Greenwood R.C., Barrat J.A., Yamaguchi A., Franchi I.A., Scott E.R.D., Bottke W.F., Gibson J.M. (2014) The oxygen isotope composition of diogenites: Evidence for early global melting on a single, compositionally diverse, HED parent body. Earth Planet. Sci. Lett. 390, 165-174.

Greenwood R.C., Barrat J.A., Scott E.R.D., Haack H., Buchanan P.C., Franchi I.A., Yamaguchi A., Johnson D., Bevan A.W.R., Burbine T.H. (2015) Geochemistry and oxygen isotope composition of main-group pallasites and olivine-rich clasts in mesosiderites: Implications for the "Great Dunite Shortage" and HED-mesosiderite connection. Geochim. Cosmochim. Acta 169, 115-136.

Greenwood R.C., Burbine T.H. and Franchi I.A. (2016) Melting and differentiation of early-formed asteroids: The perspective from high precision oxygen isotope studies. Chemie der Erde (in press)

Hallis L. J., Anand M., Greenwood R.C., Miller M. F., Franchi I.A. and Russell S.S. (2010) The oxygen isotope composition, petrology and geochemistry of mare basalts: evidence for large scale compositional variation in the lunar mantle. Geochim. Cosmochim. Acta 74, 6885-6899.

Herwartz D., Pack A., Friedrichs B., Bischoff A. (2014) Identification oft he giant impactor Theia in lunar rocks. Science 344, 1146-1150.

Hevey P.J. Sanders I.S. (2006) A model for planetesimal meltdown by ${ }^{26} \mathrm{Al}$ and its implications for meteorite parent bodies. Meteoritics Planet. Sci. 41, 95-106.

Hidaka H., Kondo T., Yoneda S. (2012) Heterogeneous isotopic anomalies of Sm and Gd in the Norton County meteorite: evidence for irradiation from the active early sun. Astrophys. J. 746, 132, doi: 10.1088/0004-637X/746/2/132.

Humayun M. (2012) Siderophile elements in the Si-bearing iron meteorites: Horse Creek, Mt. Egerton, and Tucson. $73^{\text {rd }}$ Annual Meteoritical Society Meeting, abstract \#5375.

Irving A.J, Bunch T.E., Kuehner S.M., Stimpson D. (2010) Ballen silica indicative of high shock pressures in the anomalous metal-rich Larned aubrite from Central Kansas, USA. $73^{\text {rd }}$ annual Meteoritical Society meeting, abstract \# 5309.

Jones J.H. (1995) Experimental trace element partitioning. In Rock Physics and Phase Relations: A Handbook of Physical Constants (ed. T. J. Ahrens), pp.73-104. American Geophysical Union, Washington, D.C., USA.

Javoy M., Kaminiski E., Guyot F., Andrault D., Sanloup C., Moreira M., Labrasse S., Jambon A., Agrinier P., Davaille A., Jaupart C. (2010) The chemical composition of the Earth: Enstatite chondrite models. Earth Planet. Sci. Lett. 293, 259268.

Keil K. (2010) Enstatite achondrite meteorites (aubrites) and the histories of their asteroidal parent bodies. Chem. Erde 70, $295-317$.

Keil K. and Bischoff A. (2008) Northwest Africa 2526: a partial melt residue of enstatite chondrite parentage. Meteorit. Planet. Sci. 43, 1233-1240. 
Keil K., Ntaflos Th., Taylor G.J., Brearley A.J., Newson H.E., Romig Jr. A.D. (1989) The Shallowater aubrite: evidence for origin by planetesimal impacts. Geochim. Cosmochim. Acta 53, 3291-3307.

Keil K., McCoy T.J., Wilson L., Barrat J.A., Rumble D., Meier M., Wieler R., Huss G.R. (2011) A composite Fe,Ni-FeS and enstatite-forsterite-diopside-glass vitrophyre clast in the Larkman Nunatak 04316 aubrite: Origin by pyroclastic volcanism. Meteoritics and Planetary Sci. 46, 1719-1741.

Keil K., Stöffler D., Love S.G., Scott E.R.D. (1997) Constraints on the role of impact heating and melting in asteroids. Meteorit. Planet. Sci. 32, 349-363.

Lipschutz, M.E., Verkouteren, R.M., Sears, D.W.G., Hasan, F.A., Prinz, M., Weisberg, M.K., Nehru, C.E., Delaney, J.S., Grossman, L., Boily, M. (1988) Cumberland Falls chondritic inclusions: III. Consortium study of relationship to inclusions in Allan Hills 78113 aubrite. Geochim. Cosmochim Acta 52, 1835-1848.

Lodders K. (1996) An experimental and theoretical study of the rare-earth-element partitioning between sulfides (FeS, CaS) and silicate and applications to enstatite achondrites. Meteoritics Planet. Sci. 31, 749-766.

Lodders K., Palme H., Wlotzka F. (1993) Trace elements in mineral separates of the Peña Blanca Spring aubrite: implications fort he evolution oft he aubrite parent body. Meteoritics 28, 538-551.

Lorenzetti, S., Eugster, O., Busemann, H., Marti, K., Burbine, T.H., McCoy, T. (2003) History and origin of aubrites. Geochim. Cosmochim. Acta 67, 557-571.

Masuda A. (1967) Lanthanides in the Norton County achondrite. Geochem. J. 2, 111-135.

McCall G.J.H. (1965) A meteorite of unique type: the Mount Egerton stony-iron. Mineral Mag. 35, 241-249.

McCoy T.J. (1998) A pyroxene-oldhamite clast in Bustee: Igneous aubritic oldhamite and a mechanism for the Ti enrichment in aubritic troilite. Antarctic Meteorite Res. 11, 34-50.

McCoy T.J., Dickinson T.L., Lofgren G.E. (1999) Partial melting of the Indarch (EH4) meteorite: a textural, chemical and phase relations view of melting and melt migration. Meteorit. Planet. Sci. 34, 735-746.

McCoy T.J., Dickinson T.L., Burbine T.H. (2000) Rare earth elements in coexisting sulfides in the Allan Hills 84008 aubrite: clues to aubrite genesis (abstract). Meteorit. Planet. Sci. 35 (Suppl.), A105-A106.

McCoy T.J., Mittlefehldt D.W., Wilson L. (2006) Asteroidal Differentiation in Meteorites and the Early Solar System II, D. S. Lauretta and H. Y. McSween Jr. (eds), University of Arizona Press, Tucson, 943 pp., p. 733-745.

Moynier F., Paniello R., Gounelle M., Albare'de F., Beck P., Podosek F. and Zanda B. (2011) Nature of volatile depletion and genetic relationships in enstatite chondrites and aubrites inferred from $\mathrm{Zn}$ isotopes. Geochim. Cosmochim. Acta 75, 297-397.

Miller M.F. (2002) Isotopic fractionation and the quantification of ${ }^{17} \mathrm{O}$ anomalies in the oxygen three isotopes system: an appraisal and geochemical significance. Geochim. Cosmochim. Acta 66, 1881-1889.

Miller M.F., Franchi I.A., Sexton A.S., Pillinger C.T. (1999) High precision ${ }^{17}$ O isotope measurements of oxygen from silicates and other oxides: Method and applications. Rapid Commun. Mass Spectrom. 13,1211-1217.

Miura, Y.N., Hidaka, H., Nishiizumi, K., Kusakabe, M. (2007) Noble gas and oxygen isotope studies of aubrites: a clue to origin and histories. Geochim. Cosmochim. Acta 71, 251-270.

Neal, C.W., Lipschutz, M.E. (1981) Cumberland falls chondritic inclusions: mineralogy/petrology of a forsterite chondrite suite. Geochim. Cosmochim. Acta 45, 2091-2107.

Newsom H.E., Ntaflos Th., Keil K. (1996) Dark clasts in the Khor Temiki aubrite: not basalts. Meteorit. Planet. Sci. 31, 146151.

Newton J., Franchi I.A., Pillinger C.T. (2000) The oxygen-isotopic record of enstatite meteorites. Meteoritics Planetary Sci. 35, 689-698.

Okada A., Keil K., Taylor G.J., Newsom H. (1988) Igneous history of the aubrite parent asteroid: evidence from the Norton County enstatite achondrite. Meteoritics 23, 59-74.

Petitat M., Kleine T., Touboul M., Bourdon B., Wieler R. (2008) Hf-W chronometry of aubrites and the evolution of planetary bodies. Lunar Planet. Sci. Conf. 39, abstract \#2164. 
Phinney W.C., Morrison D.A. (1990) Partition coefficients for calcic plagioclase: implications for Archean anorthosites. Geochim. Cosmochim. Acta 54, 1639-1654.

Pun A., Papike J. J., and Layne D. A. (1997) Subsolidus REE partitioning between pyroxene and plagioclase in cumulate eucrites: An ion microprobe investigations. Geochim. Cosmochim. Acta 61, 5089-5097.

Rai V.K., Jackson T.L. and Thiemens M.H. (2005) Photochemical mass-independent sulfur isotopes in achondritic meteorites. Science 309, 1062-1065.

Rubin A. E. (2010) Impact melting in the Cumberland Falls and Mayo Belwa aubrites. Meteoritics Planet. Sci. 45, 265-275.

Rubin A.E. (2015) Impact features of enstatite-rich meteorites. Chemie der Erde 75, 1-28.

Savage P.S., Moynier F. (2013) Silicon isotopic variation in enstatite meteorites: Clues to their origin and Earth-forming material. Earth Planet. Sci. Lett. 361, 487-496.

Scott E.R.D., Greenwood R.C., Franchi I.A., Sanders I.S. (2009) Oxygen isotopic constraints on the origin and parent bodies of eucrites, diogenites, and howardites. Geochim. Cosmochim. Acta 73, 5835-5853.

Spicuzza M.J., Day J.M.D., Taylor L.A., Valley J.W. (2007) Oxygen isotope constraints on the origin and differentiation of the Moon. Earth Planet. Sci. Lett. 253, 254-265.

Starkey N.A., Jackson C.R.M., Greenwood R.C., Parman S., Franchi I.A., Jackson M., Fitton J.G., Suart F.M., Kurz M. and Larsen L.M. (2016) Triple oxygen isotopic composition of high ${ }^{3} \mathrm{He} /{ }^{4} \mathrm{He}$ mantle. Geochim Cosmochim Acta 176, $227-$ 238.

Taylor G.J., Keil, K., McCoy, T., Haack., H., Scott, E.R.D. (1993) Asteroid differentiation: pyroclastic volcanism to magma oceans. Meteoritics 28, 34-52.

Treiman A.H. (1996) The perils of partition: Difficulties in retrieving magma compositions from chemically equilibrated basaltic meteorites. Geochim. Cosmochim. Acta 60, 147-155.

Trinquier A., Birck J.L. and Allègre C.J. (2007) Widespread ${ }^{54} \mathrm{Cr}$ heterogeneity in the inner solar system. Astrophys. J. 655, $1179-1185$.

van Acken D., Humayun M., Brandon A.D., and Peslier A.H. (2012) Siderophile trace elements in metals and sulfides in enstatite achondrites record planetary differentiation in an enstatite chondritic parent body. Geochim. Cosmochim. Acta 83, 272-291.

van Kan Parker M., Liebscher A., Frei D., van Sijl J., van Westrenen W., Blundy J., and Franz G. (2010) Experimental and computational study of trace element distribution between orthopyroxene and anhydrous silicate melt: Substitution mechanisms and the effect of iron. Contrib. Mineral. Petrol. 159, 459-473.

Verkouteren R.M., Lipschutz M.E. (1983) Cumberland Falls chondritic inclusions-II. Trace element contents of forsterite chondrites and meteorites of similar redox state. Geochim. Cosmochim. Acta 47, 1625-1633.

Wasson J.T.(2013) No magma ocean on vesta (or elsewhere in the asteroid belt): Volatile loss from HEDs. . Lunar Planet. Sci. Conf. 44, abstract \#2836.

Watters T.R., Prinz M. (1979) Aubrites: their origin and relationship to enstatite chondrites. Proc. Lunar Planet. Sci. Conf. 10, 1073-1093.

Watters T.R., Prinz M. (1980) Mt. Egerton and the aubrite parent body. Lunar Planet.Sci 11, 1225-1226 (abstract).

Wheelock, M.M., Keil, K., Floss, C., Taylor, G.J., Crozaz, G. (1994) REE geochemistry of oldhamite-dominated clasts from the Norton County aubrite: igneous origin of oldhamite. Geochim. Cosmochim. Acta 58, 449-458.

Wilson L., Keil K. (2012) Volcanic activity on differentiated asteroids: A review and analysis. Chemie der Erde/Geochemistry 72, 289-321.

Wilson L., Keil K. (2016) Arguments for the non-existence of magma oceans in asteroids. In "Planetesimals: Early Differentiation and Consequences for Planets", edited by Linda Elkins-Tanton and Benjamin Weiss, Cambridge University Press. (in press).

Wolf R., Ebihara M., Richter G.R., Anders A. (1983) Aubrites and diogenites: trace element clues to their origin. Geochim. Cosmochim. Acta 47, 2257-2270. 
Young E.D., Kohl I.E., Warren P.H., Rubie D.C., Jacobson S.A., Morbidelli A. (2016) Oxygen isotopic evidence for vigorous mixing during the Moon-forming giant impact. Science 351, 493-496.

Zhang J., Dauphas N., Davis A.M., Leya I., Fedkin A. (2012) The proto-Earth as a significant source of lunar material. Nature Geoscience 5, 251-255.

898 


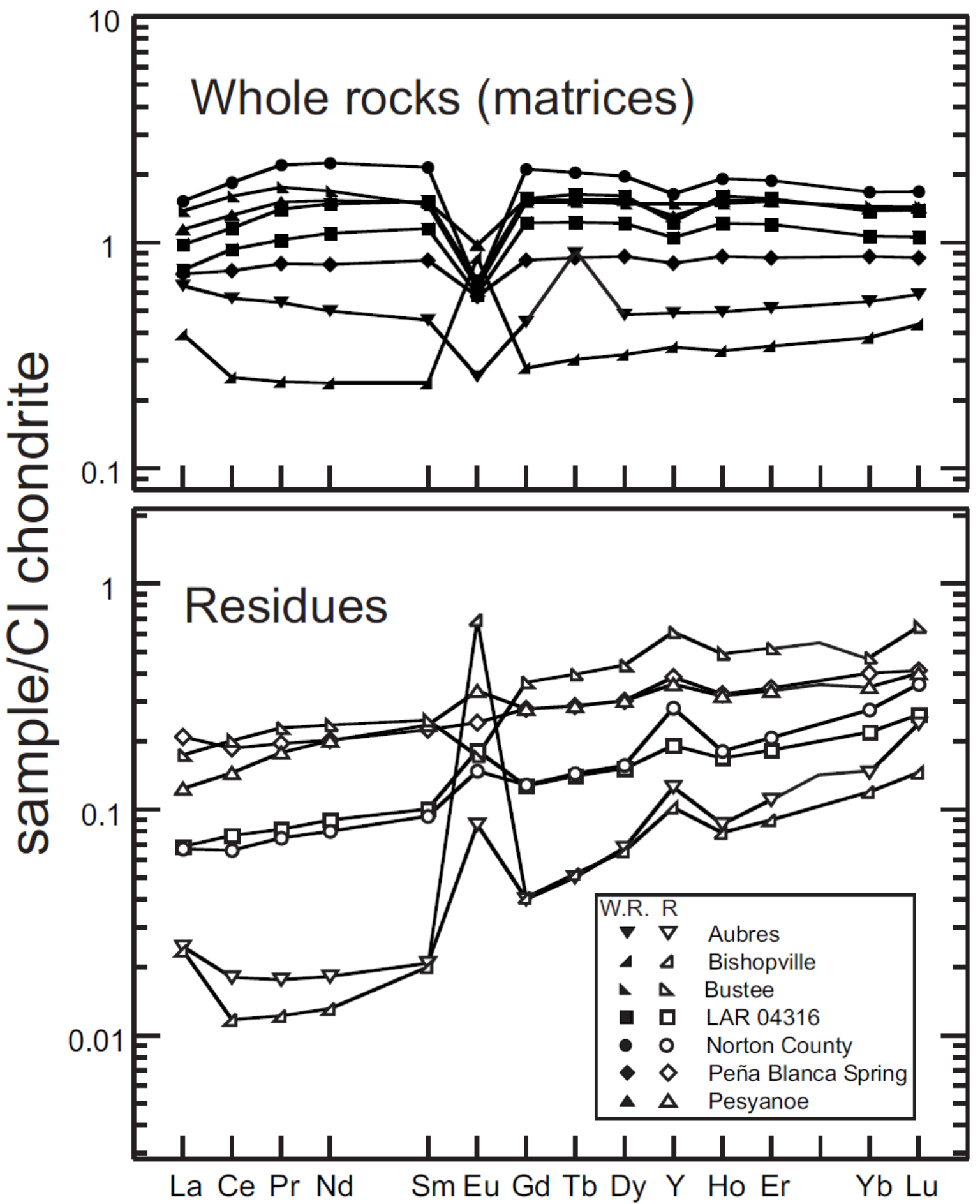

902

903

Fig. 1. REE+Y patterns of main-group aubrites and their residues after leaching (silicate fractions), normalized 905 to CI chondrite (Barrat et al., 2012). 


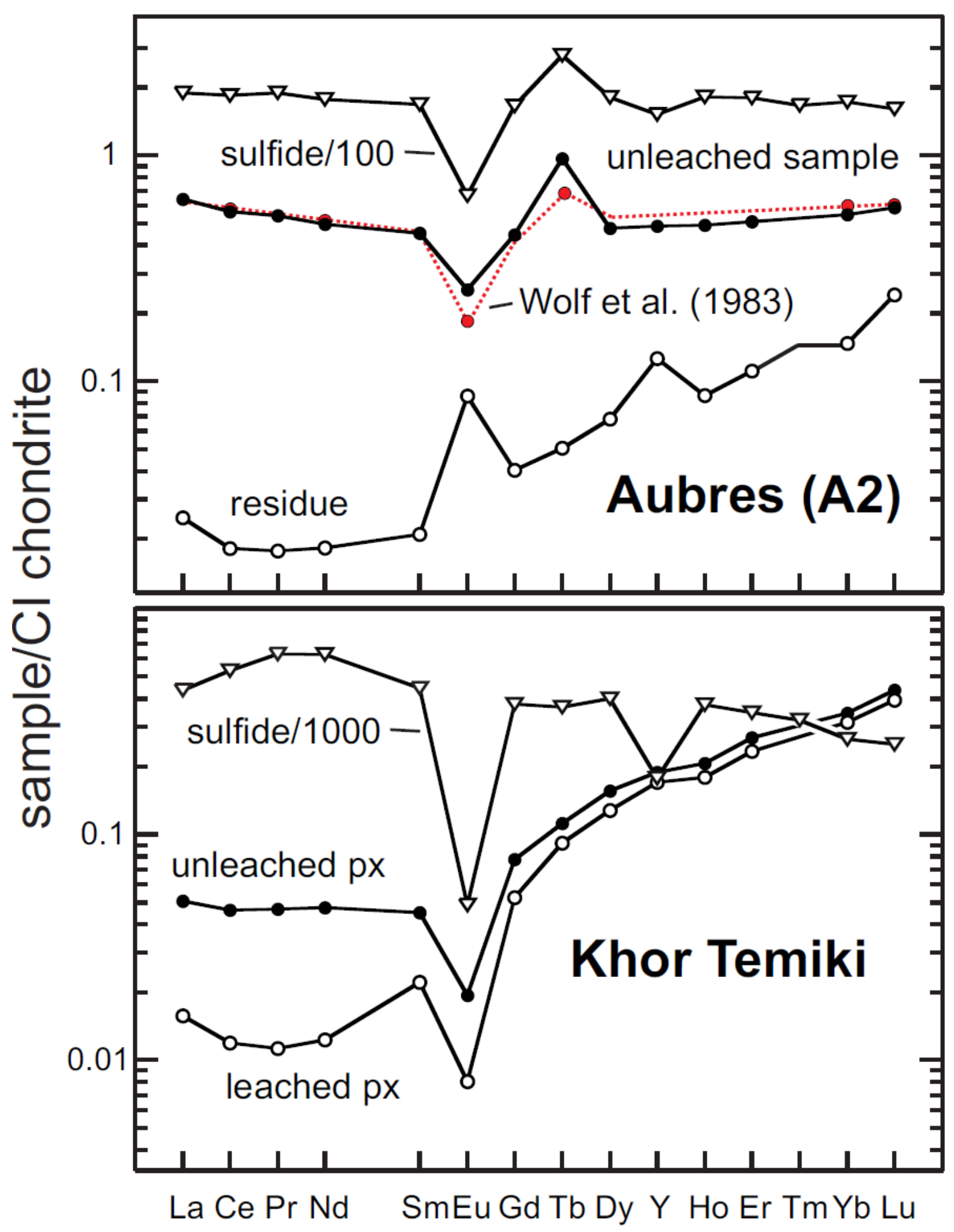

Fig. 2. REE+Y patterns of Aubres (whole rock), and Khor Temiki (pyroxene), the residues after leaching, and the leachates (assumed to be oldhamite), normalized to CI chondrite (Barrat et al., 2012). Notice that the REE abundances obtained by Wolf et al. (1983) and drawn in red, are similar to our results including the Tb concentration. 


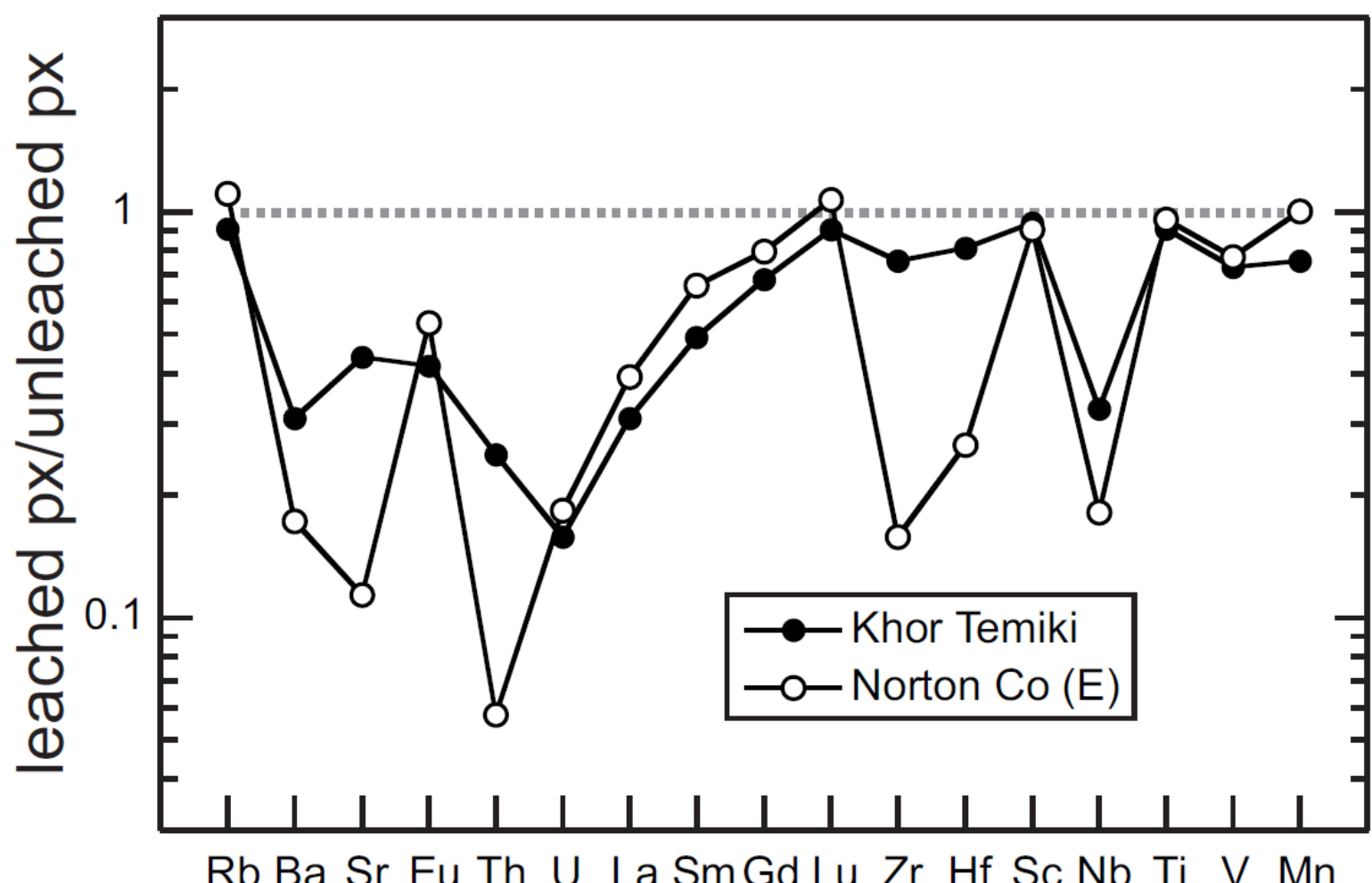

Fig. 3. Trace element patterns of two leached aubritic pyroxenes normalized to the concentrations of the unleached fractions. Elements are arranged in order of increasing ionic radii. 

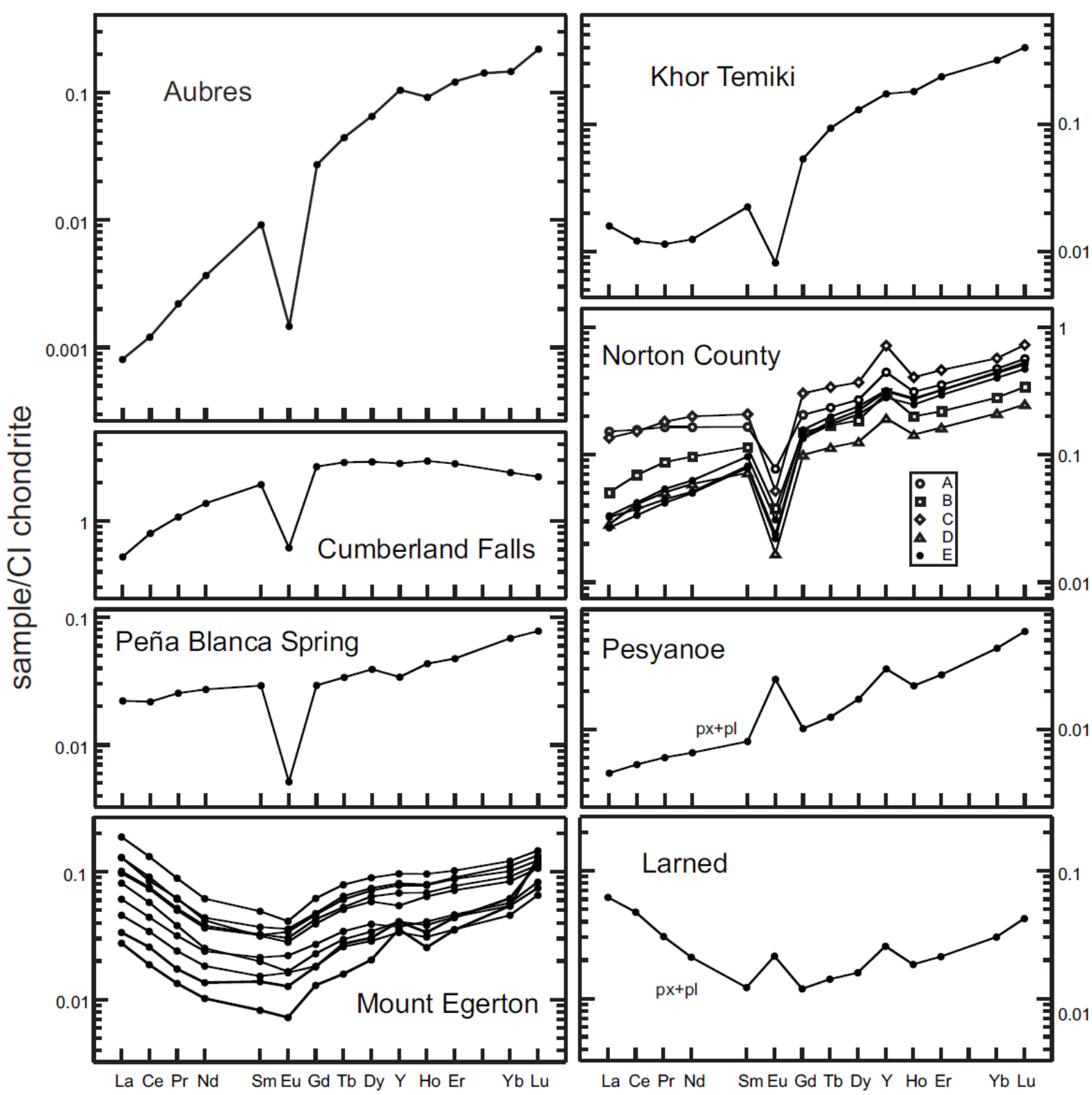

Fig. 4. REE+Y patterns of leached aubritic pyroxenes, normalized to CI chondrite (Barrat et al., 2012). 

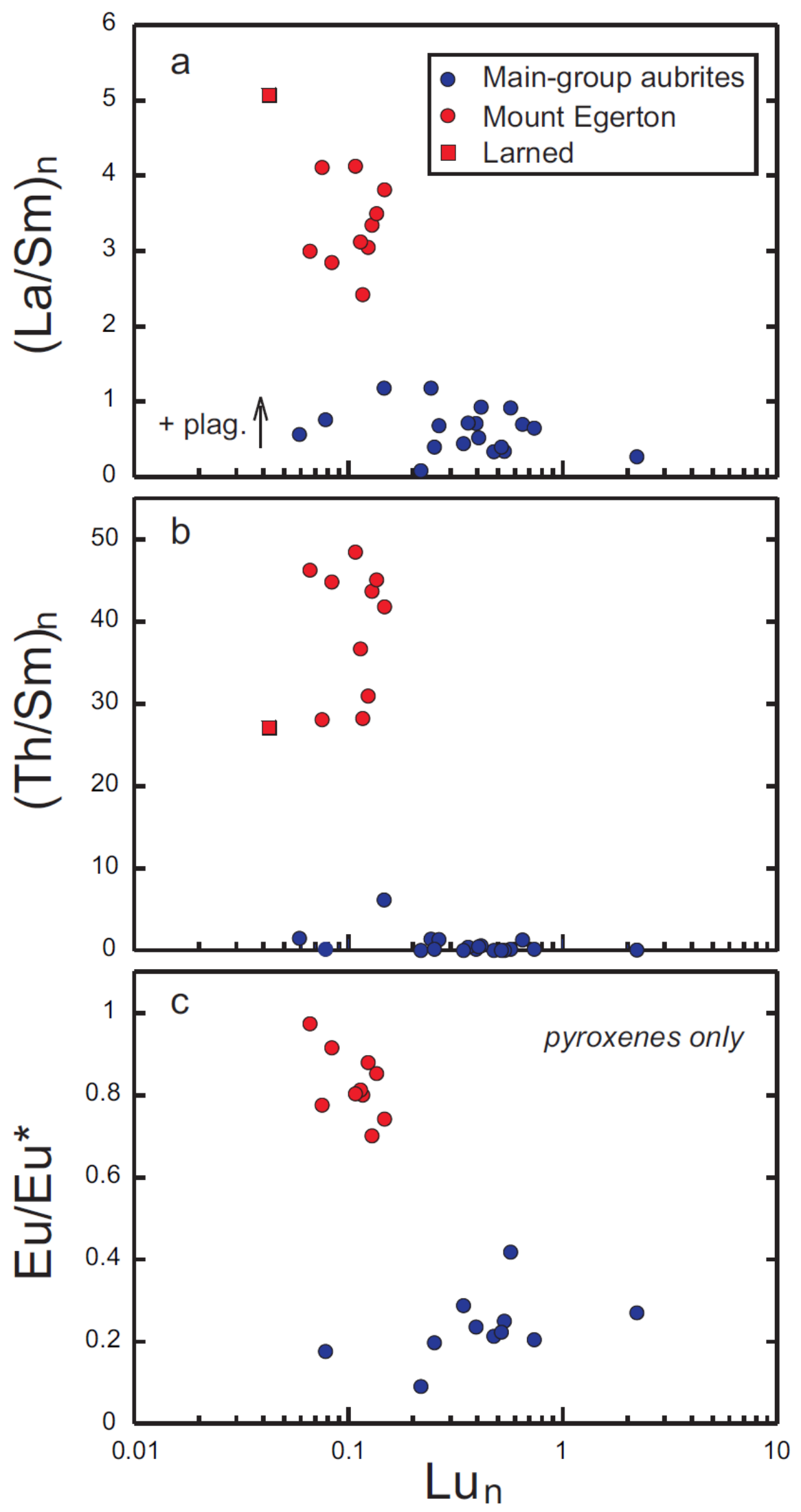

Fig. 5. $(\mathrm{La} / \mathrm{Sm})_{\mathrm{n}}$ and $(\mathrm{Th} / \mathrm{Sm})_{\mathrm{n}}$ and $\mathrm{Eu} / \mathrm{Eu}^{*} \mathrm{vs.}^{\mathrm{Lu}} \mathrm{n}_{\mathrm{n}}$ plots for the silicate fractions of aubrites, and $\mathrm{Eu} / \mathrm{Eu}^{*} \mathrm{vs} . \mathrm{Lu}_{\mathrm{n}}$ plot for leached pyroxenes. 

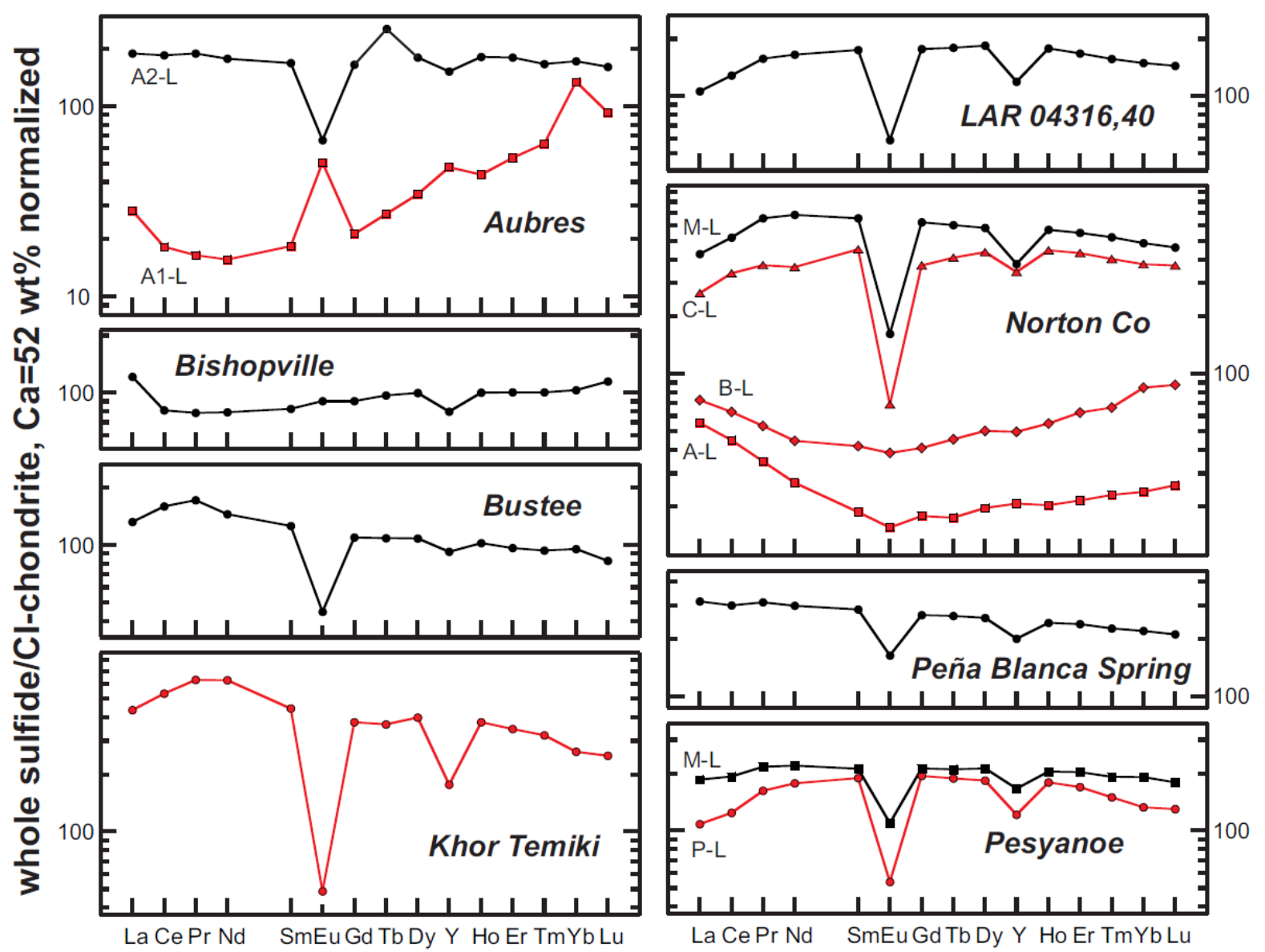

Fig. 6. REE+Y patterns of whole sulfides obtained from main-group aubrites calculated from the compositions of the leachates obtained with whole rocks (black) or with pyroxenes (red), and normalized to CI chondrite (Barrat et al., 2012). 


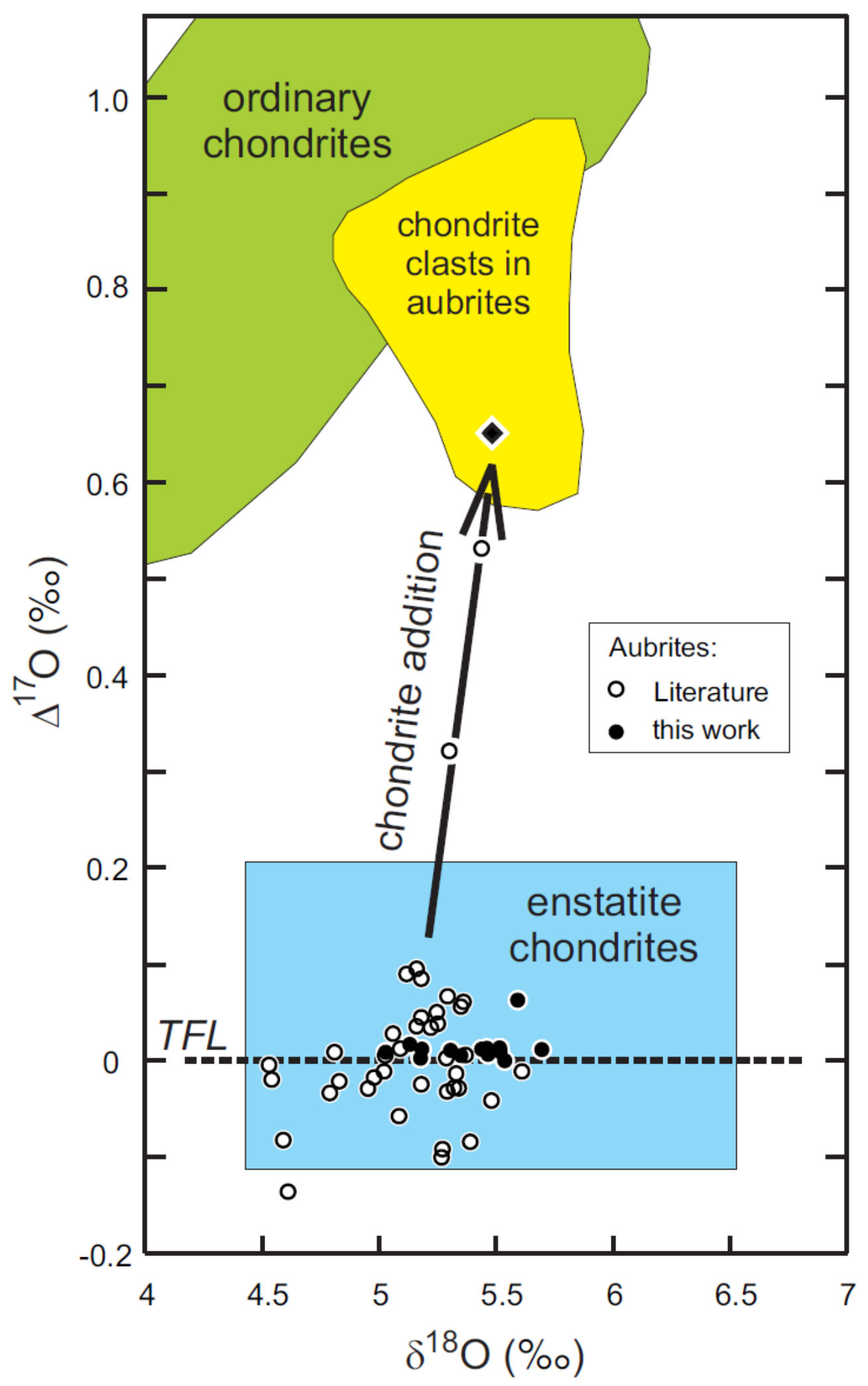

Fig. 7. $\Delta^{17} \mathrm{O}$ vs. $\delta^{18} \mathrm{O}$ plot for aubrites (Clayton and Mayeda, 1996; Newton et al., 2000; Miura et al., 2006; Keil et al., 2011, and this work). Chondritic fields are drawn with data obtained by Clayton et al. (1991), Newton et al. (2000), and Herwartz et al. (2014). 


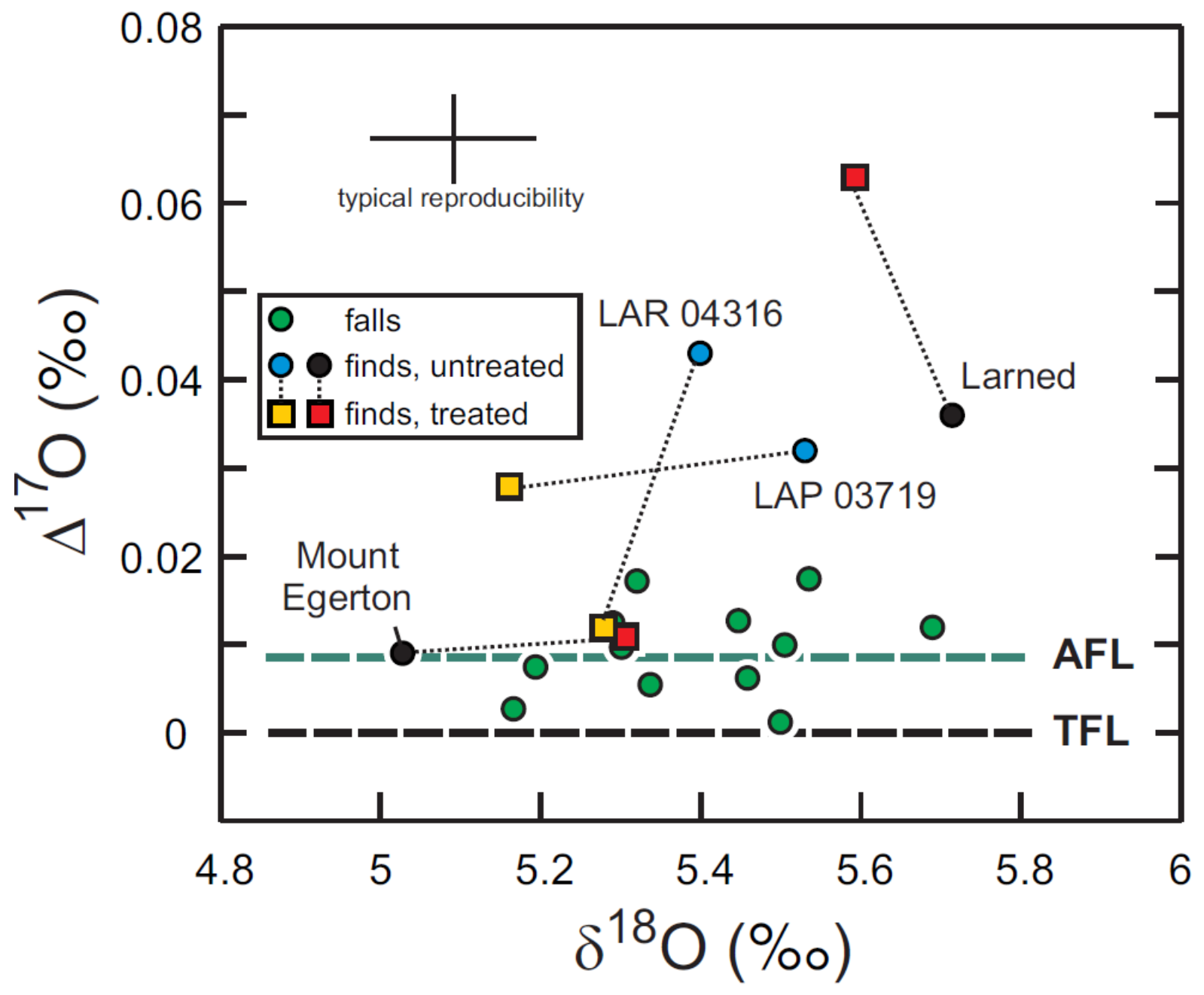

Fig. 8. $\Delta^{17} \mathrm{O}$ vs. $\delta^{18} \mathrm{O}$ plot for aubrites (this work only). 

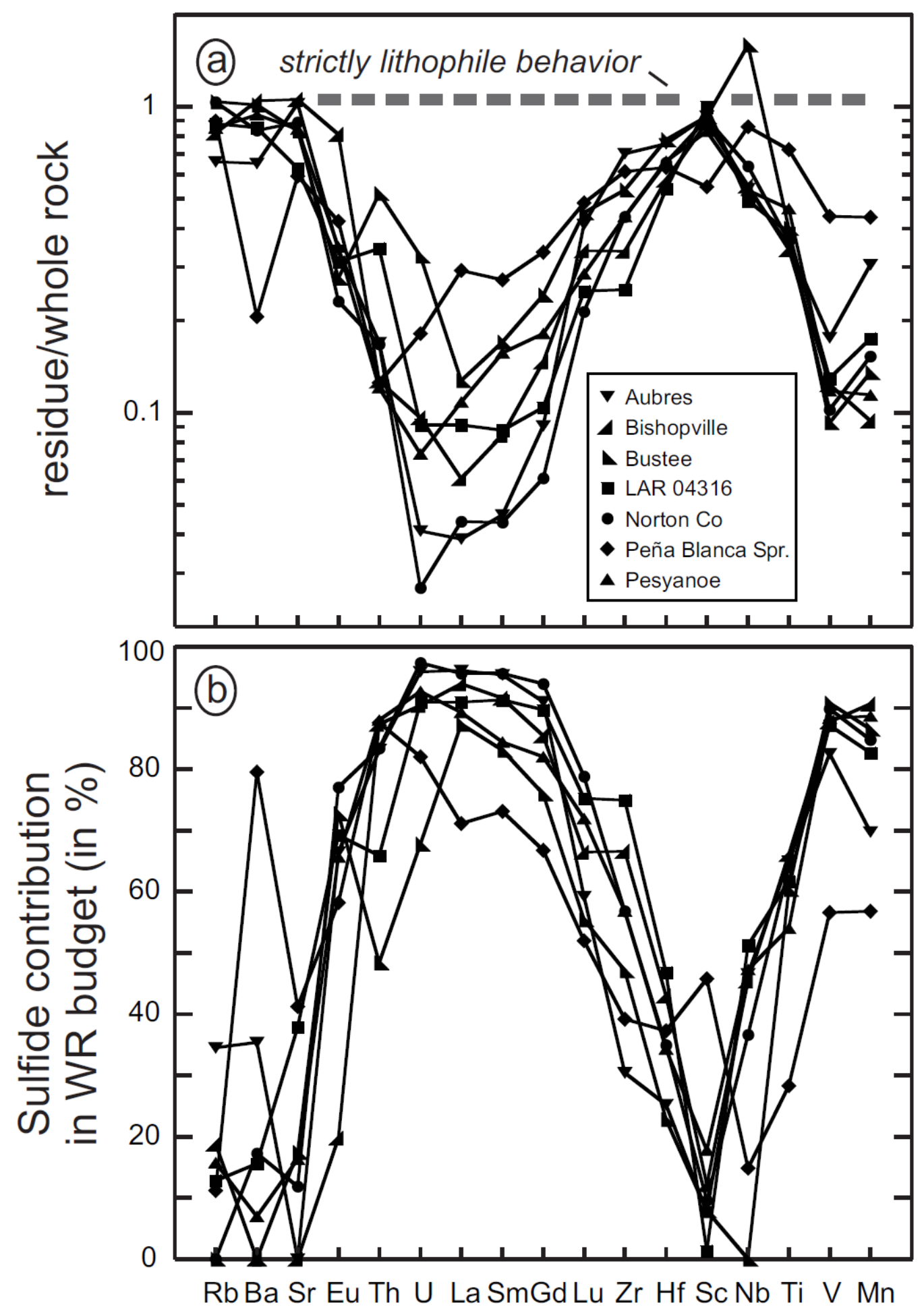

Fig. 9. a. Trace element patterns of residues obtained from "regular" aubrites, and normalized to the respective whole rock compositions. b. Sulfide contribution in whole rock budget for the same aubrites and calculated for selected trace elements. Elements are arranged in order of increasing ionic radii. See the text for discussion. 

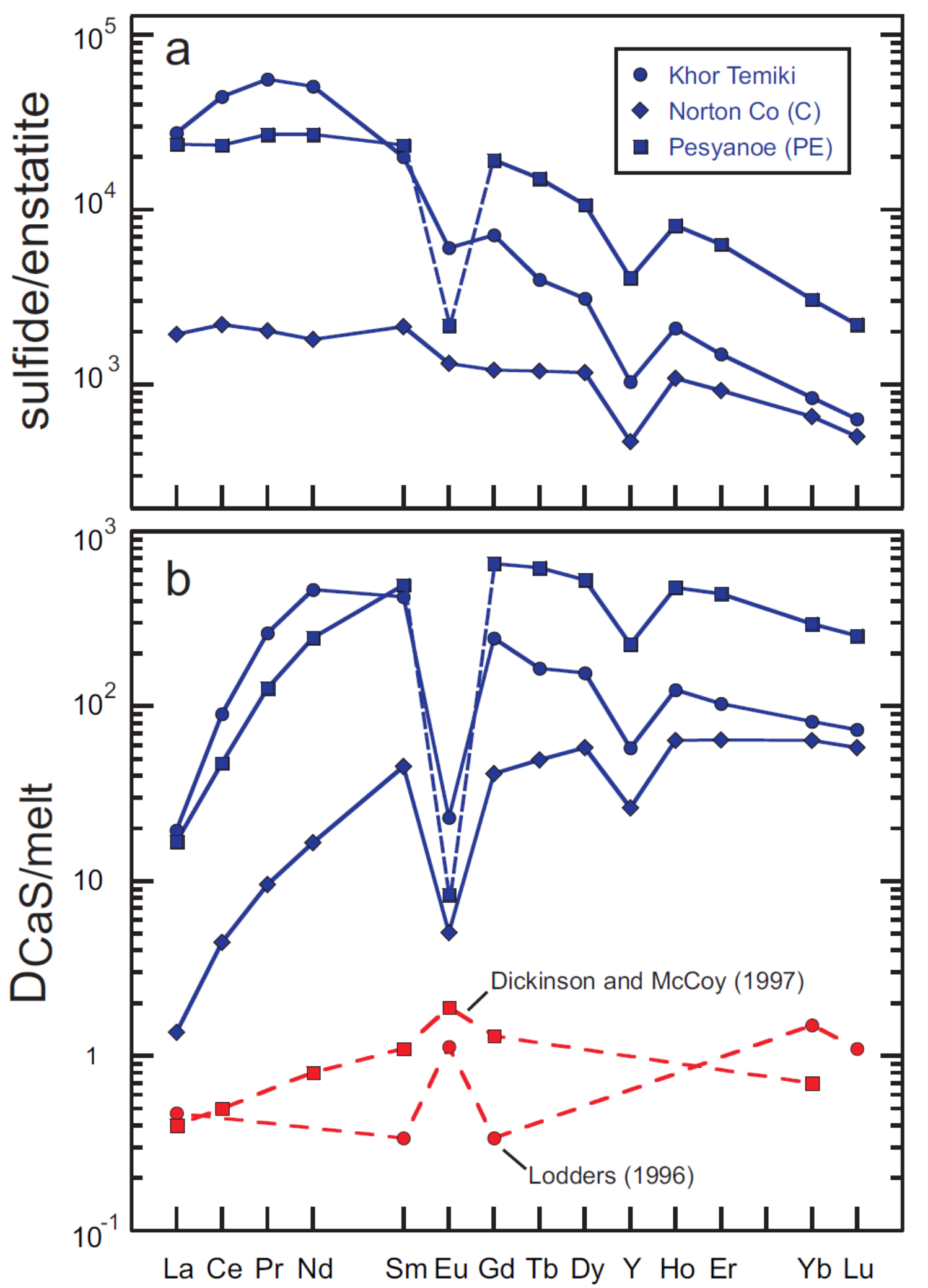

Fig. 10. a. Apparent sulfide/enstatite partition coefficient calculated for Khor Temiki, Norton County, and Pesyanoe. b. apparent oldhamite/melt partition coefficients deduced from the three previous mineral pairs and from the enstatite/melt partition coefficients obtained by van Kan Parker et al. (2010). $\mathrm{D}_{\mathrm{Eu}}$ is assumed to be similar to $\mathrm{D}_{\mathrm{Sr}}$ at very low $f \mathrm{O}_{2}$. The experimental oldhamite partition coefficients obtained by Lodders (1996) and Dickinson and McCoy (1997) are shown for comparison. 


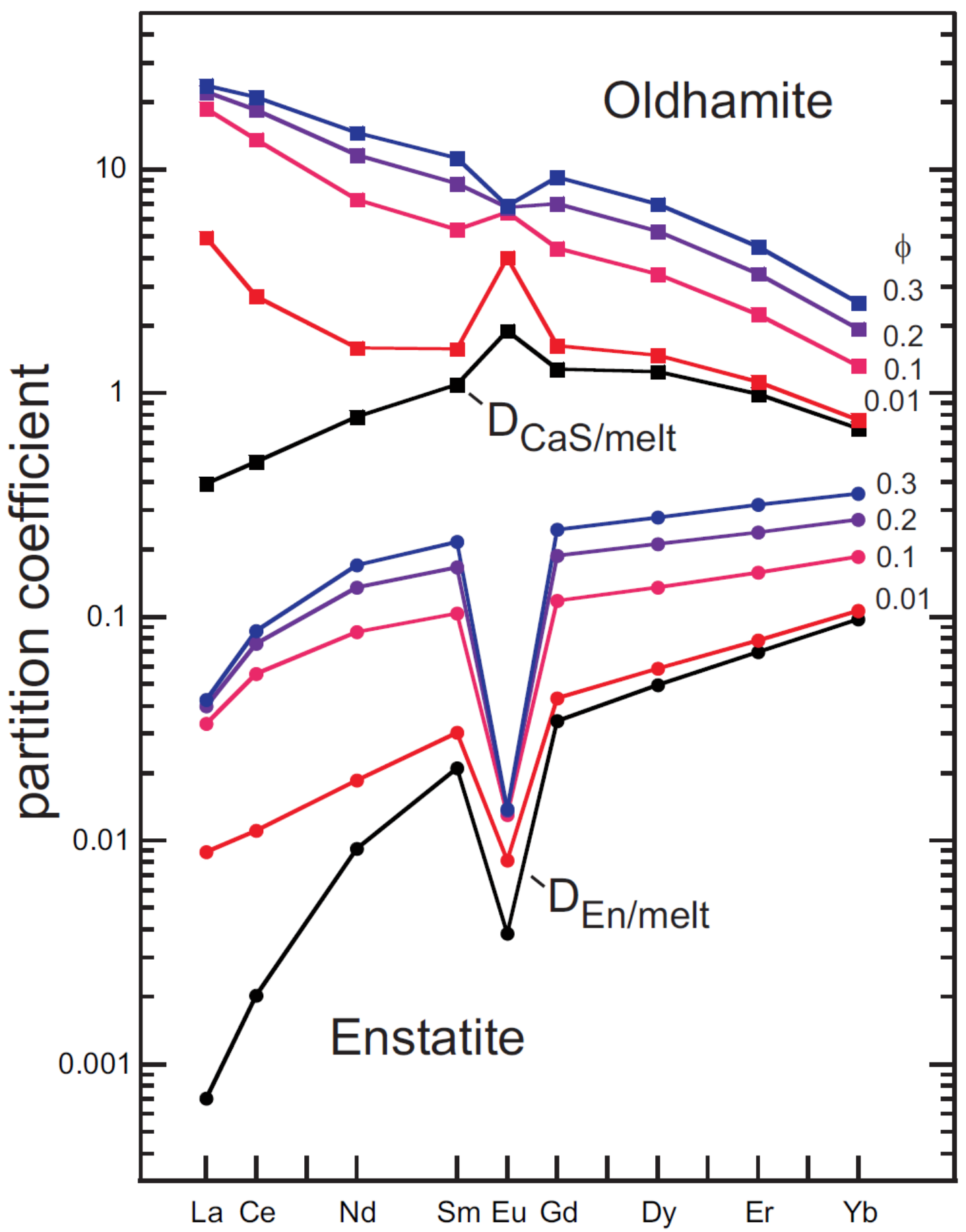

Fig.11. Apparent partition coefficients for oldhamite and enstatite. They are calculated for a hypothetical cumulate containing only cumulus enstatite and mass fractions of trapped melt $(\phi)$ ranging from 0 to 0.3 , that crystallized $90 \mathrm{wt} \%$ enstatite, $7 \mathrm{wt} \%$ plagioclase, and $3 \mathrm{wt} \%$ oldhamite. The equilibrium partition coefficients for enstatite are deduced from the values given by van Kan Parker et al. (2010) assuming that $\mathrm{D}_{\mathrm{Eu}}=\mathrm{D}_{\mathrm{Sr}}$ at very low $f \mathrm{O}_{2}$. The plagioclase/melt partition coefficients are from Phinney and Morrison (1990) except for Eu, taken from Jones (1995). The oldhamite partition coefficients are from Dickinson and McCoy (1997). 
Table 1. Details of meteorite samples studied (IOM: Institute of Meteoritics, Albuquerque; MNHN : Muséum National d'Histoire Naturelle, Paris; MWG : Meteorite Working Group, NASA; NHM: Natural History Museum, London).

\begin{tabular}{|c|c|c|c|c|c|}
\hline & Fall? & $\#$ & source & mass & Remarks \\
\hline Aubres & yes & A1 & Vernadsky Inst. & $0.160 \mathrm{~g}$ & pyroxene clast \\
\hline Aubres & yes & $\mathrm{A} 2$ & NHM, London & $0.307 \mathrm{~g}$ & Chip (matrix) \\
\hline Aubres & yes & $\mathrm{OU}$ & NHM, London & & \\
\hline Bishopville & yes & & NHM, London & $0.318 \mathrm{~g}$ & Chip (matrix) \\
\hline Bishopville & yes & $\mathrm{OU}$ & NHM, London & & \\
\hline Bustee & yes & & NHM, London & $0.293 \mathrm{~g}$ & Chip (matrix) \\
\hline Bustee & yes & $\mathrm{OU}$ & NHM, London & & \\
\hline Cumberland Falls & yes & $\mathrm{P}$ & MNHN, Paris & $0.5 \mathrm{~g}$ & pyroxene clast \\
\hline Cumberland Falls & yes & $\mathrm{Ch}$ & MNHN, Paris & $1 \mathrm{~g}$ & chondrite clast \\
\hline Khor Temiki & yes & $\mathrm{P}$ & NHM, London & $0.312 \mathrm{~g}$ & pyroxene clast \\
\hline Khor Temiki & yes & OU & NHM, London & & \\
\hline LAP 03719 & no & ,26 & MWG & & chip \\
\hline LAR 04316 & no &, 40 & MWG & $2 g$ & Large chip (matrix) \\
\hline Larned & no & & D. Stimpson & $0.5 \mathrm{~g}$ & Pyroxenes with plagio. traces \\
\hline Mayo Belwa & yes & $\mathrm{OU}$ & NHM, London & & \\
\hline Mount Egerton & no & A to $\mathrm{D}$ & J.A. Barrat & $\approx 0.6 \mathrm{~g}$ each & 4 distinct enstatite clasts, subsequently split. \\
\hline Norton County & yes & M & IOM & $5 \mathrm{~g}$ & Large chip (matrix) \\
\hline Norton County & yes & A to D & J.A. Barrat & $\approx 0.3 \mathrm{~g}$ each & 4 distinct pyroxene clasts \\
\hline Norton County & yes & $\mathrm{E}$ & IOM & $2.27 \mathrm{~g}$ & large pyroxene crystal, subsequently split. \\
\hline Norton County & yes & $\mathrm{F}$ & JAB & $1 \mathrm{~g}$ & matrix \\
\hline Norton County & yes & G & $\mathrm{OU}$ & $0.5 \mathrm{~g}$ & matrix \\
\hline Peña Blanca Spr. & yes & M & IOM & $3.5 \mathrm{~g}$ & Large chip (matrix) \\
\hline Peña Blanca Spr. & yes & $\mathrm{P}$ & MNHN, Paris & $0.2 \mathrm{~g}$ & pyroxene clast \\
\hline Peña Blanca Spr. & yes & $\mathrm{OU}$ & NHM, London & & \\
\hline Pesyanoe & yes & M & Vernadsky Inst. & $0.409 \mathrm{~g}$ & Large chip \\
\hline Pesyanoe & yes & $\mathrm{P}$ & Vernadsky Inst. & $0.222 \mathrm{~g}$ & Pyroxene with plagioclase traces \\
\hline
\end{tabular}


Table 2. Trace element abundances in aubrites in $\mu \mathrm{g} / \mathrm{g}$ (WR : whole rock ("matrix"), R : residue, n.d.: not determined).

\begin{tabular}{|c|c|c|c|c|c|c|c|c|c|c|c|c|c|c|}
\hline & & Aubres & Aubres & Aubres & Bishopville & Bishopville & Bustee & Bustee & Cumberland & Khor Temiki & Khor Temiki & LAR 04316 & LAR 04316 & Larned \\
\hline & & A1 & A2 & A2 & & & & & Falls & & & & & \\
\hline & & $\mathrm{px}, \mathrm{R}$ & WR, U & $\mathrm{WR}, \mathrm{R}$ & WR, U & WR, R & WR, U & WR, R & $\mathrm{px}, \mathrm{R}$ & $\mathrm{px}, \mathrm{U}$ & $\mathrm{px}, \mathrm{R}$ & WR, U & WR, R & $\mathrm{px}, \mathrm{R}$ \\
\hline $\mathrm{Sc}$ & $\mu \mathrm{g} / \mathrm{g}$ & 6.34 & 5.65 & 5.26 & 4.80 & 4.26 & 6.31 & 5.87 & 14.45 & 4.17 & 3.91 & 6.91 & 5.15 & 2.48 \\
\hline $\mathrm{Ti}$ & $\mu \mathrm{g} / \mathrm{g}$ & 101 & 173 & 61 & 269 & 92 & 315 & 126 & 289 & 116 & 105 & 257 & 120 & 17 \\
\hline $\mathrm{V}$ & $\mu \mathrm{g} / \mathrm{g}$ & 2.40 & 6.68 & 1.18 & 6.21 & 0.767 & 8.40 & 0.78 & 1.81 & 2.91 & 2.12 & 8.40 & 1.23 & 1.09 \\
\hline Mn & $\mu \mathrm{g} / \mathrm{g}$ & 654 & 1005 & 307 & 927 & 87 & 1221 & 166 & 353 & 572 & 433 & 2024 & 354 & 149 \\
\hline $\mathrm{Rb}$ & $\mathrm{ng} / \mathrm{g}$ & n.d. & 396 & 262 & 1470 & 1205 & 545 & 566 & 198 & 100 & 90.8 & 1344 & 1206 & 213 \\
\hline $\mathrm{Sr}$ & $\mathrm{ng} / \mathrm{g}$ & 3.3 & 1173 & 1201 & 10506 & 11077 & 2220 & 1852 & 3174 & 59.9 & 26.2 & 4440 & 2862 & 250 \\
\hline Y & $\mathrm{ng} / \mathrm{g}$ & 163 & 760 & 197 & 538 & 160 & 2325 & 957 & 4394 & 294 & 266 & 1923 & 302 & 40.3 \\
\hline $\mathrm{Zr}$ & $\mathrm{ng} / \mathrm{g}$ & 17.9 & 423 & 297 & 3021 & 1020 & 2084 & 1113 & 213 & 64.6 & 48.9 & 1740 & 549 & 574 \\
\hline $\mathrm{Nb}$ & $\mathrm{ng} / \mathrm{g}$ & 0.6 & 22.1 & 11.9 & 26.8 & 14.8 & 157 & 250 & 62.6 & 3.3 & 1.1 & 19.5 & 64.1 & 37.2 \\
\hline Cs & $\mathrm{ng} / \mathrm{g}$ & n.d. & 84.6 & 43.2 & 40.8 & 27.7 & 31.7 & 25.4 & n.d. & 4.57 & 2.66 & 61.7 & 37.2 & 11.9 \\
\hline $\mathrm{Ba}$ & $\mathrm{ng} / \mathrm{g}$ & $<1$ & 449 & 293 & 3654 & 3820 & 700 & 710 & 415 & 98.3 & 30.5 & 1229 & 1057 & 552 \\
\hline $\mathrm{La}$ & $\mathrm{ng} / \mathrm{g}$ & 0.19 & 151 & 5.84 & 92.2 & 5.62 & 324 & 41.2 & 122 & 11.9 & 3.70 & 230 & 16.3 & 14.6 \\
\hline $\mathrm{Ce}$ & $\mathrm{ng} / \mathrm{g}$ & 0.73 & 339 & 10.9 & 151 & 7.07 & 958 & 122 & 479 & 27.8 & 7.17 & 696 & 46.3 & 28.7 \\
\hline $\operatorname{Pr}$ & $\mathrm{ng} / \mathrm{g}$ & 0.20 & 49.4 & 1.61 & 22.0 & 1.11 & 160 & 21.0 & 97.4 & 4.25 & 1.03 & 128 & 7.47 & 2.80 \\
\hline $\mathrm{Nd}$ & $\mathrm{ng} / \mathrm{g}$ & 1.67 & 231 & 8.48 & 111 & 6.12 & 783 & 110 & 636 & 21.9 & 5.72 & 688 & 41.9 & 9.83 \\
\hline $\mathrm{Sm}$ & $\mathrm{ng} / \mathrm{g}$ & 1.42 & 69.3 & 3.22 & 36.5 & 3.09 & 225 & 38.2 & 295 & 6.91 & 3.39 & 233 & 15.45 & 1.88 \\
\hline $\mathrm{Eu}$ & $\mathrm{ng} / \mathrm{g}$ & 0.085 & 14.9 & 5.05 & 50.3 & 40.8 & 37.0 & 10.2 & 35.9 & 1.13 & 0.472 & 39.7 & 10.7 & 1.27 \\
\hline $\mathrm{Gd}$ & $\mathrm{ng} / \mathrm{g}$ & 5.53 & 91.6 & 8.32 & 57.4 & 8.44 & 311 & 75.7 & 549 & 15.9 & 10.8 & 322 & 26.3 & 2.47 \\
\hline $\mathrm{Tb}$ & $\mathrm{ng} / \mathrm{g}$ & 1.66 & 36.4 & 1.89 & 11.4 & 1.95 & 56.5 & 14.9 & 108 & 4.19 & 3.44 & 61.3 & 5.32 & 0.535 \\
\hline Dy & $\mathrm{ng} / \mathrm{g}$ & 16.7 & 121 & 17.3 & 81.0 & 16.7 & 378 & 111 & 737 & 39.5 & 32.5 & 409 & 38.7 & 4.07 \\
\hline Ho & $\mathrm{ng} / \mathrm{g}$ & 5.14 & 27.8 & 4.90 & 18.7 & 4.49 & 84.2 & 27.9 & 167 & 11.7 & 10.1 & 90.9 & 9.60 & 1.05 \\
\hline $\mathrm{Er}$ & $\mathrm{ng} / \mathrm{g}$ & 20.0 & 84.6 & 18.4 & 57.5 & 15.0 & 252 & 86.5 & 465 & 44.5 & 38.6 & 259 & 30.7 & 3.55 \\
\hline $\mathrm{Yb}$ & $\mathrm{ng} / \mathrm{g}$ & 24.3 & 91.9 & 24.7 & 63.8 & 20.2 & 243 & 79.3 & 402 & 57.8 & 52.8 & 232 & 37.2 & 5.11 \\
\hline $\mathrm{Lu}$ & $\mathrm{ng} / \mathrm{g}$ & 5.35 & 14.4 & 5.94 & 10.6 & 3.61 & 35.4 & 15.9 & 54.5 & 10.7 & 9.69 & 34.3 & 6.50 & 1.05 \\
\hline $\mathrm{Hf}$ & $\mathrm{ng} / \mathrm{g}$ & 0.69 & 17.1 & 12.9 & 111 & 64.0 & 52.9 & 41.2 & 15.4 & 2.70 & 2.19 & 63.8 & 33.9 & 25.1 \\
\hline $\mathrm{Pb}$ & $\mathrm{ng} / \mathrm{g}$ & 1.4 & 517 & 1.1 & 126 & 2.3 & 578 & 8.3 & n.d. & 15.0 & n.d. & 17.6 & 0.18 & 13 \\
\hline Th & $\mathrm{ng} / \mathrm{g}$ & n.d. & 4.81 & 0.82 & 27.7 & 3.53 & 17.9 & 9.36 & 3.08 & 0.42 & 0.10 & 15.8 & 3.82 & 9.43 \\
\hline $\mathrm{U}$ & $\mathrm{ng} / \mathrm{g}$ & n.d. & 4.47 & 0.18 & 3.29 & 0.32 & 13.3 & 4.34 & 0.94 & 0.28 & 0.04 & 5.47 & 0.36 & 5.66 \\
\hline$(\mathrm{La} / \mathrm{Lu}) \mathrm{n}$ & & 0.0037 & 1.09 & 0.10 & 0.91 & 0.16 & 0.96 & 0.27 & 0.23 & 0.12 & 0.04 & 0.70 & 0.26 & 1.46 \\
\hline $\mathrm{Eu} / \mathrm{Eu}^{*}$ & & 0.09 & 0.57 & 2.96 & 3.33 & 24.19 & 0.42 & 0.57 & 0.27 & 0.33 & 0.24 & 0.44 & 1.61 & 1.78 \\
\hline$(\mathrm{Y} / \mathrm{Ho}) \mathrm{n}$ & & 1.15 & 0.99 & 1.46 & 1.04 & 1.30 & 1.00 & 1.24 & 0.96 & 0.91 & 0.95 & 0.77 & 1.14 & 1.39 \\
\hline$(\mathrm{Zr} / \mathrm{Hf}) \mathrm{n}$ & & 0.79 & 0.75 & 0.70 & 0.83 & 0.48 & 1.20 & 0.82 & 0.42 & 0.73 & 0.68 & 0.83 & 0.49 & 0.69 \\
\hline
\end{tabular}


Table 2. (continue)

\begin{tabular}{|c|c|c|c|c|c|c|c|c|c|c|c|c|c|c|}
\hline & & Mt Egerton & Mt Egerton & Mt Egerton & Mt Egerton & Mt Egerton & Mt Egerton & Mt Egerton & Mt Egerton & Mt Egerton & Mt Egerton & Norton Co & Norton Co & Norton Co \\
\hline & & A1 & A2 & B1 & B2 & B3 & $\mathrm{C} 1$ & $\mathrm{C} 2$ & D1 & D2 & D3 & M & M & A \\
\hline & & $\mathrm{px}, \mathrm{R}$ & $\mathrm{px}, \mathrm{R}$ & $\mathrm{px}, \mathrm{R}$ & $\mathrm{px}, \mathrm{R}$ & $\mathrm{px}, \mathrm{R}$ & $\mathrm{px}, \mathrm{R}$ & $\mathrm{px}, \mathrm{R}$ & $\mathrm{px}, \mathrm{R}$ & $\mathrm{px}, \mathrm{R}$ & $\mathrm{px}, \mathrm{R}$ & WR, U & WR, R & $\mathrm{px}, \mathrm{R}$ \\
\hline $\mathrm{Sc}$ & $\mu \mathrm{g} / \mathrm{g}$ & 2.92 & 1.23 & 2.24 & 3.39 & 2.56 & 2.43 & 3.28 & 3.71 & 1.70 & 2.72 & 7.33 & 6.69 & 9.22 \\
\hline $\mathrm{Ti}$ & $\mu \mathrm{g} / \mathrm{g}$ & 67 & 61 & 70 & 49 & 37 & 74 & 88 & 101 & 62 & 48 & 302 & 110 & 183 \\
\hline $\mathrm{V}$ & $\mu \mathrm{g} / \mathrm{g}$ & 0.975 & 0.863 & 0.761 & 0.692 & 0.555 & 0.743 & 0.874 & 0.957 & 0.767 & 0.619 & 9.62 & 0.987 & 1.02 \\
\hline Mn & $\mu \mathrm{g} / \mathrm{g}$ & 238 & 181 & 117 & 123 & 97 & 101 & 97 & 111 & 129 & 104 & 1300 & 199 & 248 \\
\hline $\mathrm{Rb}$ & $\mathrm{ng} / \mathrm{g}$ & 156 & 165 & 350 & 212 & 182 & 509 & 513 & 638 & 341 & 341 & 357 & 370 & n.d. \\
\hline $\mathrm{Sr}$ & $\mathrm{ng} / \mathrm{g}$ & 27.3 & 18.4 & 86.3 & 37.0 & 76.7 & 116 & 103 & 167 & 46.7 & 103 & 1394 & 1241 & 372 \\
\hline Y & $\mathrm{ng} / \mathrm{g}$ & 55.7 & 63.9 & 123 & 52.7 & 58.3 & 107 & 128 & 151 & 64.0 & 85.4 & 2561 & 442 & 701 \\
\hline $\mathrm{Zr}$ & $\mathrm{ng} / \mathrm{g}$ & 286 & 459 & 1377 & 959 & 754 & 1451 & 2290 & 2035 & 1023 & 1022 & 684 & 298 & 68.9 \\
\hline $\mathrm{Nb}$ & $\mathrm{ng} / \mathrm{g}$ & 82.9 & 70.7 & 163 & 82.2 & 53.4 & 177 & 191 & 233 & 120 & 91.4 & 27.6 & 17.7 & 19.2 \\
\hline Cs & $\mathrm{ng} / \mathrm{g}$ & 3.84 & 3.39 & 17.0 & 6.24 & 17.90 & 26.4 & 28.0 & 25.8 & 16.4 & 25.9 & 24.4 & 22.5 & n.d. \\
\hline $\mathrm{Ba}$ & $\mathrm{ng} / \mathrm{g}$ & 362 & 367 & 1114 & 647 & 903 & 1554 & 1664 & 2558 & 874 & 1643 & 326 & 273 & 219 \\
\hline $\mathrm{La}$ & $\mathrm{ng} / \mathrm{g}$ & 6.52 & 7.92 & 23.1 & 10.8 & 14.4 & 23.9 & 30.5 & 44.3 & 19.3 & 30.7 & 358 & 15.8 & 36.2 \\
\hline $\mathrm{Ce}$ & $\mathrm{ng} / \mathrm{g}$ & 11.3 & 15.6 & 44.6 & 20.7 & 26.6 & 45.8 & 55.2 & 79.3 & 34.7 & 51.5 & 1105 & 39.8 & 95.4 \\
\hline $\operatorname{Pr}$ & $\mathrm{ng} / \mathrm{g}$ & 1.22 & 1.59 & 4.58 & 2.19 & 2.90 & 4.74 & 5.59 & 8.15 & 3.49 & 5.69 & 201 & 6.85 & 15.2 \\
\hline $\mathrm{Nd}$ & $\mathrm{ng} / \mathrm{g}$ & 4.76 & 6.33 & 17.0 & 8.55 & 11.2 & 17.7 & 20.4 & 28.7 & 11.8 & 19.5 & 1045 & 37.4 & 77.3 \\
\hline $\mathrm{Sm}$ & $\mathrm{ng} / \mathrm{g}$ & 1.27 & 2.13 & 4.92 & 2.35 & 3.29 & 4.99 & 5.67 & 7.56 & 3.06 & 4.84 & 329 & 14.4 & 25.6 \\
\hline $\mathrm{Eu}$ & $\mathrm{ng} / \mathrm{g}$ & 0.427 & 0.745 & 1.99 & 0.957 & 1.30 & 1.78 & 2.10 & 2.42 & 0.977 & 1.66 & 37.7 & 8.73 & 4.58 \\
\hline $\mathrm{Gd}$ & $\mathrm{ng} / \mathrm{g}$ & 2.67 & 3.73 & 9.54 & 3.77 & 5.62 & 8.81 & 9.80 & 12.8 & 4.74 & 8.10 & 435 & 26.6 & 42.9 \\
\hline $\mathrm{Tb}$ & $\mathrm{ng} / \mathrm{g}$ & 0.597 & 1.03 & 2.29 & 0.977 & 1.29 & 1.99 & 2.43 & 3.00 & 1.12 & 1.91 & 76.7 & 5.44 & 8.89 \\
\hline Dy & $\mathrm{ng} / \mathrm{g}$ & 5.22 & 7.77 & 18.2 & 7.33 & 9.96 & 16.3 & 19.0 & 23.0 & 8.71 & 15.0 & 498 & 40.0 & 69.1 \\
\hline Но & $\mathrm{ng} / \mathrm{g}$ & 1.46 & 1.91 & 4.46 & 1.76 & 2.32 & 3.92 & 4.54 & 5.47 & 2.18 & 3.65 & 108 & 10.3 & 17.9 \\
\hline $\mathrm{Er}$ & $\mathrm{ng} / \mathrm{g}$ & 5.84 & 7.32 & 14.7 & 5.91 & 7.72 & 12.9 & 15.0 & 17.1 & 7.41 & 12.0 & 311 & 34.7 & 59.4 \\
\hline $\mathrm{Yb}$ & $\mathrm{ng} / \mathrm{g}$ & 9.17 & 10.5 & 17.1 & 7.72 & 9.64 & 15.5 & 18.8 & 20.5 & 9.13 & 14.2 & 281 & 46.8 & 80.1 \\
\hline $\mathrm{Lu}$ & $\mathrm{ng} / \mathrm{g}$ & 3.16 & 2.86 & 3.03 & 1.62 & 2.06 & 2.79 & 3.32 & 3.63 & 1.86 & 2.64 & 41.4 & 8.86 & 14.0 \\
\hline $\mathrm{Hf}$ & $\mathrm{ng} / \mathrm{g}$ & 10.7 & 15.5 & 45.1 & 30.7 & 30.6 & 49.7 & 73.3 & 67.2 & 32.0 & 43.3 & 23.4 & 15.4 & 3.25 \\
\hline $\mathrm{Pb}$ & $\mathrm{ng} / \mathrm{g}$ & 4.2 & 3.5 & 20.9 & 8.4 & 8.44 & 23.6 & 32.9 & 41.4 & 11.0 & 18.8 & 45.3 & 9.37 & 2.67 \\
\hline Th & $\mathrm{ng} / \mathrm{g}$ & 10.3 & 11.1 & 28.2 & 20.1 & 27.4 & 33.9 & 47.4 & 58.5 & 15.9 & 43.5 & 6.80 & 1.14 & 0.86 \\
\hline $\mathrm{U}$ & $\mathrm{ng} / \mathrm{g}$ & 3.25 & 6.22 & 12.7 & 6.06 & 8.60 & 14.4 & 18.2 & 18.9 & 8.30 & 14.0 & 7.91 & 0.21 & 0.66 \\
\hline$(\mathrm{La} / \mathrm{Lu}) \mathrm{n}$ & & 0.22 & 0.29 & 0.80 & 0.70 & 0.73 & 0.90 & 0.96 & 1.28 & 1.09 & 1.22 & 0.91 & 0.19 & 0.27 \\
\hline $\mathrm{Eu} / \mathrm{Eu}^{*}$ & & 0.70 & 0.80 & 0.88 & 0.97 & 0.92 & 0.81 & 0.85 & 0.74 & 0.78 & 0.81 & 0.30 & 1.35 & 0.42 \\
\hline (Y/Ho)n & & 1.39 & 1.21 & 1.00 & 1.09 & 0.91 & 0.99 & 1.02 & 1.00 & 1.07 & 0.85 & 0.86 & 1.55 & 1.42 \\
\hline$(\mathrm{Zr} / \mathrm{Hf}) \mathrm{n}$ & & 0.82 & 0.90 & 0.93 & 0.95 & 0.75 & 0.89 & 0.95 & 0.92 & 0.97 & 0.72 & 0.89 & 0.59 & 0.64 \\
\hline
\end{tabular}


Table 2. (continue)

\begin{tabular}{|c|c|c|c|c|c|c|c|c|c|c|c|c|c|c|}
\hline & & $\begin{array}{c}\text { Norton Co } \\
\text { B } \\
\text { px, R }\end{array}$ & $\begin{array}{c}\text { Norton Co } \\
\text { C } \\
\text { px, R }\end{array}$ & $\begin{array}{c}\text { Norton Co } \\
\text { D } \\
\text { px, R }\end{array}$ & $\begin{array}{c}\text { Norton Co } \\
\text { E1 } \\
\text { px, U }\end{array}$ & $\begin{array}{c}\text { Norton Co } \\
\text { E2 } \\
\text { px, R }\end{array}$ & $\begin{array}{c}\text { Norton Co } \\
\text { E3 } \\
\text { px, R }\end{array}$ & $\begin{array}{c}\text { Norton Co } \\
\text { E4 } \\
\text { px, R }\end{array}$ & $\begin{array}{c}\text { Peña Blanca } \\
\text { Spring, M } \\
\text { WR, U }\end{array}$ & $\begin{array}{c}\text { Peña Blanca } \\
\text { Spring, M } \\
\text { WR, R }\end{array}$ & $\begin{array}{c}\text { Peña Blanca } \\
\text { Spring, P } \\
\text { px, R }\end{array}$ & $\begin{array}{c}\text { Pesyanoe } \\
\text { M } \\
\text { WR, U }\end{array}$ & $\begin{array}{c}\text { Pesyanoe } \\
\text { M } \\
\text { WR, R }\end{array}$ & $\begin{array}{c}\text { Pesyanoe } \\
\mathrm{P} \\
\text { px, R }\end{array}$ \\
\hline $\mathrm{Sc}$ & $\mu \mathrm{g} / \mathrm{g}$ & 9.95 & 10.42 & n.d. & 6.89 & 7.54 & 4.58 & 6.57 & 5.36 & 2.94 & 2.98 & 7.89 & 6.55 & 3.37 \\
\hline $\mathrm{Ti}$ & $\mu \mathrm{g} / \mathrm{g}$ & 156 & 214 & 55 & 159 & 165 & 140 & 150 & 149 & 108 & 68 & 310 & 144 & 29 \\
\hline $\mathrm{V}$ & $\mu \mathrm{g} / \mathrm{g}$ & 1.07 & 1.12 & 0.298 & 2.16 & 1.78 & 1.55 & 1.68 & 4.23 & 1.86 & 4.00 & 9.13 & 1.08 & 0.315 \\
\hline $\mathrm{Mn}$ & $\mu \mathrm{g} / \mathrm{g}$ & 223 & 225 & 60 & 522 & 466 & 425 & 443 & 732 & 319 & 586 & 1877 & 215 & 45 \\
\hline $\mathrm{Rb}$ & $\mathrm{ng} / \mathrm{g}$ & 28.3 & 978 & 6.51 & 47.0 & 54.6 & 52.6 & 49.0 & 573 & 514 & 106 & 2221 & 1891 & 61.9 \\
\hline $\mathrm{Sr}$ & $\mathrm{ng} / \mathrm{g}$ & 180 & 408 & 73.2 & 206 & 53.2 & 8.82 & 8.34 & 4592 & 2724 & 53.6 & 5009 & 4234 & 461 \\
\hline $\mathrm{Y}$ & $\mathrm{ng} / \mathrm{g}$ & 478 & 1127 & 305 & 499 & 503 & 442 & 494 & 1262 & 605 & 53.1 & 2042 & 562 & 46.6 \\
\hline $\mathrm{Zr}$ & $\mathrm{ng} / \mathrm{g}$ & 16.0 & 158 & 26.6 & 64.4 & 13.5 & 8.40 & 8.60 & 1645 & 1010 & 45 & 2875 & 1255 & 154 \\
\hline $\mathrm{Nb}$ & $\mathrm{ng} / \mathrm{g}$ & 0.85 & 0.77 & 17.9 & 4.86 & 0.877 & 1.16 & 0.61 & 11.2 & 9.64 & 1.70 & 20.7 & 11.0 & 1.85 \\
\hline Cs & $\mathrm{ng} / \mathrm{g}$ & n.d. & 59.2 & n.d. & 3.06 & 5.98 & 5.58 & 5.46 & 287 & 346 & 96.8 & 62.2 & 46.1 & 3.16 \\
\hline $\mathrm{Ba}$ & $\mathrm{ng} / \mathrm{g}$ & n.d. & n.d. & 2.86 & 117 & 26.2 & 15.3 & 19.2 & 2795 & 576 & 31.3 & 1835 & 1725 & 207 \\
\hline $\mathrm{La}$ & $\mathrm{ng} / \mathrm{g}$ & 12.0 & 32.2 & 6.75 & 18.6 & 7.89 & 6.34 & 7.68 & 170 & 49.5 & 5.21 & 269 & 29.2 & 1.07 \\
\hline $\mathrm{Ce}$ & $\mathrm{ng} / \mathrm{g}$ & 42.0 & 92.3 & 24.8 & 55.0 & 25.5 & 20.3 & 22.7 & 449 & 113 & 13.1 & 793 & 87.8 & 3.19 \\
\hline $\operatorname{Pr}$ & $\mathrm{ng} / \mathrm{g}$ & 8.03 & 16.7 & 4.64 & 9.47 & 4.95 & 3.85 & 4.11 & 73.4 & 17.9 & 2.31 & 137 & 16.3 & 0.548 \\
\hline $\mathrm{Nd}$ & $\mathrm{ng} / \mathrm{g}$ & 45.5 & 93.4 & 27.7 & 51.1 & 29.6 & 23.5 & 24.0 & 369 & 94.4 & 12.7 & 712 & 94.4 & 3.05 \\
\hline $\mathrm{Sm}$ & $\mathrm{ng} / \mathrm{g}$ & 17.7 & 32.1 & 11.1 & 20.2 & 14.9 & 12.2 & 12.6 & 127 & 34.6 & 4.45 & 231 & 36.4 & 1.23 \\
\hline $\mathrm{Eu}$ & $\mathrm{ng} / \mathrm{g}$ & 2.24 & 3.06 & 0.99 & 2.85 & 1.83 & 1.30 & 1.42 & 33.9 & 14.3 & 0.301 & 57.0 & 19.8 & 1.45 \\
\hline $\mathrm{Gd}$ & $\mathrm{ng} / \mathrm{g}$ & 31.3 & 63.3 & 20.7 & 37.5 & 32.6 & 28.0 & 29.1 & 172 & 57.7 & 6.02 & 318 & 57.7 & 2.09 \\
\hline $\mathrm{Tb}$ & $\mathrm{ng} / \mathrm{g}$ & 6.44 & 12.8 & 4.32 & 7.91 & 7.54 & 6.55 & 6.89 & 32.1 & 10.8 & 1.27 & 57.8 & 10.9 & 0.47 \\
\hline Dy & $\mathrm{ng} / \mathrm{g}$ & 47.8 & 94.9 & 32.5 & 61.6 & 61.2 & 53.2 & 57.0 & 219 & 77.3 & 9.94 & 392 & 77.3 & 4.40 \\
\hline Но & $\mathrm{ng} / \mathrm{g}$ & 11.4 & 23.2 & 8.22 & 15.3 & 15.9 & 14.1 & 15.6 & 49.0 & 18.5 & 2.45 & 86.3 & 18.1 & 1.25 \\
\hline $\mathrm{Er}$ & $\mathrm{ng} / \mathrm{g}$ & 36.8 & 77.3 & 27.4 & 52.5 & 54.0 & 49.4 & 53.8 & 141 & 57.5 & 7.87 & 253 & 56.0 & 4.46 \\
\hline $\mathrm{Yb}$ & $\mathrm{ng} / \mathrm{g}$ & 47.6 & 96.7 & 35.8 & 67.1 & 75.2 & 68.1 & 74.0 & 146 & 67.8 & 11.6 & 237 & 58.8 & 7.31 \\
\hline $\mathrm{Lu}$ & $\mathrm{ng} / \mathrm{g}$ & 8.45 & 18.1 & 6.18 & 11.7 & 13.1 & 11.7 & 12.7 & 21.1 & 10.2 & 1.92 & 35.0 & 9.93 & 1.45 \\
\hline $\mathrm{Hf}$ & $\mathrm{ng} / \mathrm{g}$ & 1.26 & 7.38 & 1.46 & 2.63 & 0.859 & 0.62 & 0.62 & 72.0 & 45.6 & 0.59 & 113 & 74.7 & 9.70 \\
\hline $\mathrm{Pb}$ & $\mathrm{ng} / \mathrm{g}$ & n.d. & 10.7 & 0.5 & 1480 & 10.2 & 1.18 & 210 & 296 & 5.02 & 0.55 & 52.1 & 4.20 & 3.53 \\
\hline Th & $\mathrm{ng} / \mathrm{g}$ & 0.079 & 0.78 & 0.32 & 1.07 & 0.058 & 0.072 & 0.053 & 28.7 & 3.59 & 0.130 & 27.9 & 3.37 & 0.35 \\
\hline $\mathrm{U}$ & $\mathrm{ng} / \mathrm{g}$ & 0.097 & 0.16 & 0.11 & 0.44 & 0.08 & 0.076 & 0.088 & 11.8 & 2.15 & 0.111 & 7.79 & 0.57 & 0.07 \\
\hline$(\mathrm{La} / \mathrm{Lu}) \mathrm{n}$ & & 0.15 & 0.19 & 0.11 & 0.17 & 0.063 & 0.057 & 0.063 & 0.84 & 0.51 & 0.28 & 0.80 & 0.31 & 0.077 \\
\hline $\mathrm{Eu} / \mathrm{Eu}^{*}$ & & 0.29 & 0.21 & 0.20 & 0.31 & 0.25 & 0.21 & 0.22 & 0.69 & 0.97 & 0.18 & 0.64 & 1.31 & 2.73 \\
\hline (Y/Ho)n & & 1.52 & 1.76 & 1.35 & 1.18 & 1.15 & 1.13 & 1.15 & 0.93 & 1.19 & 0.79 & 0.86 & 1.13 & 1.36 \\
\hline$(\mathrm{Zr} / \mathrm{Hf}) \mathrm{n}$ & & 0.39 & 0.65 & 0.55 & 0.74 & 0.48 & 0.41 & 0.42 & 0.69 & 0.67 & 2.32 & 0.78 & 0.51 & 0.48 \\
\hline
\end{tabular}


Table 3. Trace element abundances (in $\mu \mathrm{g} / \mathrm{g}$ ) in leachates, normalized to $\mathrm{Ca}=52 \mathrm{wt} \%$.

\begin{tabular}{|c|c|c|c|c|c|c|c|c|c|c|c|c|c|c|c|c|c|c|}
\hline & $\mathrm{Y}$ & $\mathrm{La}$ & $\mathrm{Ce}$ & $\operatorname{Pr}$ & $\mathrm{Nd}$ & $\mathrm{Sm}$ & $\mathrm{Eu}$ & $\mathrm{Gd}$ & $\mathrm{Tb}$ & Dy & Ho & $\mathrm{Er}$ & $\mathrm{Tm}$ & $\mathrm{Yb}$ & $\mathrm{Lu}$ & Th & $\mathrm{U}$ & $(\mathrm{Y} / \mathrm{Ho})_{\mathrm{n}}$ \\
\hline Aubres A1 & 74.44 & 6.62 & 10.94 & 1.5 & 7.26 & 2.82 & 2.96 & 4.39 & 1.01 & 8.73 & 2.47 & 8.89 & 1.62 & 22.56 & 2.28 & 0.324 & 0.226 & 1.09 \\
\hline Aubres A2 & 237 & 44.49 & 111 & 17.22 & 82.38 & 25.76 & 3.89 & 34.09 & 10.42 & 45.83 & 10.26 & 29.92 & 4.24 & 28.97 & 3.96 & 1.25 & 1.36 & 0.84 \\
\hline Bishopville & 124 & 28.49 & 48.49 & 7.13 & 36.62 & 12.62 & 5.31 & 18.64 & 3.64 & 25.31 & 5.67 & 16.7 & 2.56 & 17.31 & 2.82 & 10.15 & 1.23 & 0.79 \\
\hline Bustee & 144 & 31.07 & 95.94 & 15.66 & 67.5 & 19.24 & 2.62 & 22.6 & 4.08 & 27.6 & 5.79 & 16.03 & 2.38 & 16.04 & 2.03 & 1.12 & 0.99 & 0.90 \\
\hline Khor Temiki & 276 & 102 & 319 & 57.19 & 290 & 67.96 & 2.85 & 77.61 & 13.74 & 101 & 21.29 & 57.54 & 8.17 & 44.22 & 6.16 & 3.22 & 3.11 & 0.47 \\
\hline LAR 04316 & 186 & 24.89 & 77.04 & 14.32 & 76.8 & 26.69 & 3.45 & 36.35 & 6.72 & 46.72 & 10.09 & 27.88 & 3.99 & 25.09 & 3.55 & 1.83 & 0.65 & 0.67 \\
\hline Norton Co, M & 589 & 100 & 312 & 59.66 & 318 & 101 & 9.49 & 128 & 22.66 & 148 & 32.29 & 91.31 & 13.28 & 81.71 & 11.33 & 2.31 & 2.91 & 0.66 \\
\hline Norton Co, A & 32.45 & 13 & 26.86 & 3.16 & 12.42 & 2.88 & 0.91 & 3.69 & 0.66 & 5.01 & 1.15 & 3.59 & 0.589 & 4.04 & 0.64 & 1.66 & 4.09 & 1.02 \\
\hline Norton Co, B & 77.39 & 17.08 & 37.83 & 4.84 & 20.64 & 6.38 & 2.25 & 8.4 & 1.7 & 12.73 & 3.11 & 10.39 & 1.69 & 14.21 & 2.15 & 0.714 & 0.763 & 0.90 \\
\hline Norton Co, C & 534 & 62.21 & 203 & 33.81 & 169 & 69.00 & 4.04 & 76.31 & 15.3 & 111 & 25.2 & 71.38 & 10.21 & 63.29 & 9.12 & 1.96 & 1.56 & 0.77 \\
\hline Pena Blanca Sp., M & 313 & 74.01 & 180 & 28.34 & 139 & 43.68 & 9.61 & 55.18 & 9.92 & 65.74 & 13.79 & 39.85 & 5.79 & 37.06 & 5.21 & 11.56 & 4.82 & 0.82 \\
\hline Pesyanoe, PE & 190 & 25.47 & 74.52 & 14.76 & 82.19 & 28.93 & 3.16 & 40.07 & 7.06 & 46.68 & 10.13 & 28.18 & 3.81 & 22.3 & 3.19 & 2.47 & 0.8 & 0.68 \\
\hline Pesyanoe, PM & 259 & 43.65 & 116 & 19.69 & 102 & 32.38 & 6.42 & 43.73 & 7.88 & 54.00 & 11.57 & 33.78 & 4.89 & 32.08 & 4.41 & 4.24 & 1.24 & 0.81 \\
\hline
\end{tabular}


Table 4. Oxygen isotope analyses of aubrites and one chondritic clast from Cumberland Falls.

\begin{tabular}{|c|c|c|c|c|c|c|c|c|c|}
\hline SAMPLE & \# & treatement & $\mathrm{N}$ & $\delta^{17} \mathrm{O}(\% \mathrm{o})$ & $\sigma$ & $\delta^{18} \mathrm{O}(\%)$ & $\sigma$ & $\Delta^{17} \mathrm{O}(\%)$ & $\sigma$ \\
\hline \multicolumn{10}{|l|}{ Falls: } \\
\hline Aubres & OU & untreated & 1 & 2.871 & & 5.466 & & 0.007 & \\
\hline Bishopville & OU & untreated & 2 & 2.997 & 0.019 & 5.696 & 0.037 & 0.012 & 0.000 \\
\hline Bustee & OU & untreated & 2 & 2.809 & 0.050 & 5.349 & 0.099 & 0.005 & 0.002 \\
\hline Khor Temiki & OU & untreated & 2 & 2.901 & 0.018 & 5.518 & 0.077 & 0.010 & 0.022 \\
\hline Mayo Belwa & $\mathrm{OU}$ & untreated & 4 & 2.923 & 0.063 & 5.547 & 0.117 & 0.017 & 0.006 \\
\hline Norton County & M & untreated & 2 & 2.808 & 0.001 & 5.327 & 0.004 & 0.017 & 0.003 \\
\hline Norton County & $\mathrm{E}$ & untreated & 3 & 2.790 & 0.158 & 5.301 & 0.282 & 0.012 & 0.012 \\
\hline Norton County & $\mathrm{F}$ & untreated & 3 & 2.793 & 0.121 & 5.314 & 0.246 & 0.009 & 0.009 \\
\hline Norton County & $\mathrm{G}$ & untreated & 4 & 2.889 & 0.015 & 5.511 & 0.035 & 0.001 & 0.011 \\
\hline Pena Blanca Spring & M & untreated & 2 & 2.716 & 0.008 & 5.177 & 0.033 & 0.003 & 0.010 \\
\hline Pena Blanca Spring & OU & untreated & 4 & 2.730 & 0.143 & 5.196 & 0.266 & 0.007 & 0.009 \\
\hline Pesyanoe matrix & $\mathrm{M}$ & untreated & 2 & 2.874 & 0.097 & 5.459 & 0.168 & 0.013 & 0.009 \\
\hline Mean values & & & & 2.842 & 0.082 & 5.405 & 0.154 & 0.009 & 0.005 \\
\hline \multicolumn{10}{|l|}{ Finds: } \\
\hline Larned & & untreated & 2 & 3.031 & 0.012 & 5.714 & 0.047 & 0.036 & 0.012 \\
\hline Larned & & $6 \mathrm{~N} \mathrm{HCl}$ & 2 & 2.994 & 0.001 & 5.592 & 0.004 & 0.063 & 0.003 \\
\hline LAP 03719 & ,26 & untreated & 1 & 2.930 & & 5.530 & & 0.032 & \\
\hline LAP 03719 & ,26 & EATG & 2 & 2.732 & 0.162 & 5.160 & 0.299 & 0.028 & 0.005 \\
\hline LAR 04316 &, 40 & untreated & 2 & 2.873 & 0.005 & 5.399 & 0.008 & 0.043 & 0.009 \\
\hline LAR 04316, &, 40 & EATG & 2 & 2.778 & 0.135 & 5.278 & 0.257 & 0.012 & 0.001 \\
\hline Mount Egerton & & untreated & 1 & 2.644 & & 5.028 & & 0.009 & \\
\hline Mount Egerton & & $6 \mathrm{~N} \mathrm{HCl}$ & 4 & 2.792 & 0.107 & 5.306 & 0.203 & 0.011 & 0.003 \\
\hline \multicolumn{10}{|l|}{ Chondritic clast: } \\
\hline Cumberland Falls & & untreated & 2 & 3.527 & 0.013 & 5.485 & 0.004 & 0.651 & 0.015 \\
\hline
\end{tabular}

